\title{
Development and Validation of a Parole Quality Assurance Inventory (PQAI)
}

\author{
by \\ Kaitlyn Wardrop
}

A thesis submitted to the Faculty of Graduate and Postdoctoral Affairs in partial fulfillment of the requirements for the degree of

Master of Arts

in

Psychology

Carleton University

Ottawa, Ontario

(C) 2015, Kaitlyn Wardrop 


\begin{abstract}
Focus on evidence-based practice in the area of parole has been increasing in recent years. The purpose of the current study was to examine aspects of paroling authorities and how they function in order to better define high quality paroling systems. In order to achieve this, the Parole Quality Assurance Inventory (PQAI) was developed to measure paroling authority quality. The psychometric properties of this scale were evaluated, as well as, efforts were made to validate this scale by examining its relationship with parole performance indicators. Thirteen paroling authorities completed the PQAI. Results found that the PQAI was unable to be validated. Although, with a large amount of removed items, the scale was able to achieve appropriate psychometric properties, there was no relationship between PQAI subscale and total scores with the proportion of offenders who failed in the community. Limitations and future directions are discussed.
\end{abstract}




\section{Acknowledgements}

I thank the members of my committee - Dr. Shelley Brown and Dr. Ralph Serin for their input, recommendations, and understanding of data collection difficulties. I also appreciate Dr. Diana Majury for taking the time to act as my external examiner and Dr. Patricia Smith for chairing my defence. I owe special thanks to my supervisor, Dr. Ralph Serin, for his guidance and contagious enthusiasm throughout this project - this endeavour could not have happened without your support!

I am grateful for the advisory panel which assisted with the development of the Parole Quality Assurance Inventory. Jean Sutton, Robbye Braxton, Cathy Banks, and Nancy Campbell provided valuable feedback which made this project all the better. As well, I would like to thank Keith Hardison for the assistance recruiting paroling authorities. It was certainly challenging at times, but I appreciated all help I could get. I would also like to extend my appreciation to all the paroling authorities who participated in the current project.

Furthermore, I am grateful for the statistical guidance Renee Gobeil and LeslieAnn Keown provided. Your feedback was greatly appreciated.

Finally, thanks to my family and friends for their support throughout this work. Your constant love and encouragement was instrumental for the completion of this project. 


\section{Table of Contents}

Development and Validation of a Parole Quality Assurance Inventory ................. 1

Offenders Under Supervision.................................................................... 4

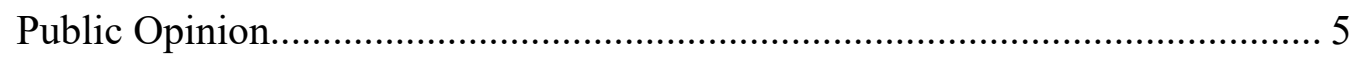

Evidence Based Policy and Practice ........................................................... 8

The Rationale for Embracing Evidence-Based Approaches ............................. 9

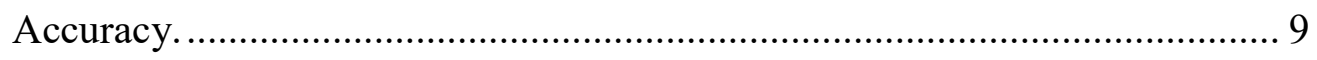

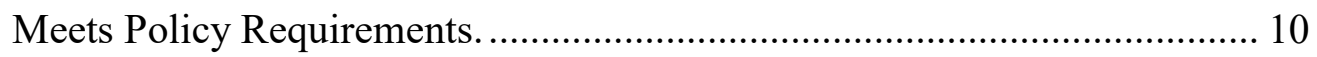

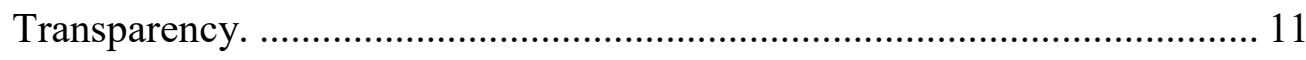

Effective and Efficient Parole Decision-making......................................... 13

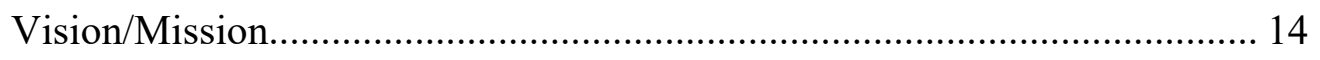

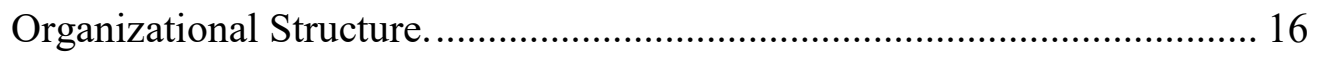

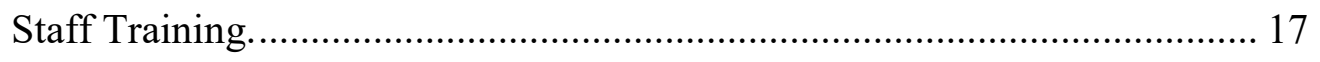

Decision-Making and Violation Process. ................................................ 19

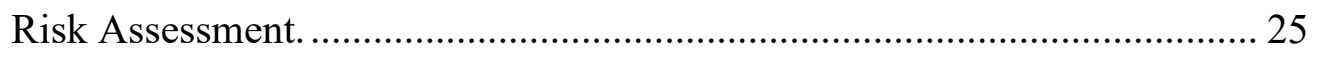

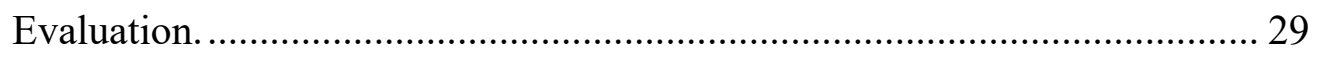

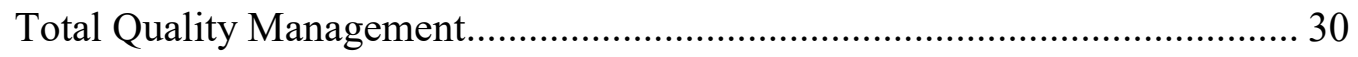

Measuring Efficient and Effective Parole Decision-Making ......................... 32

Correctional Program Assurance Inventory. .......................................... 32

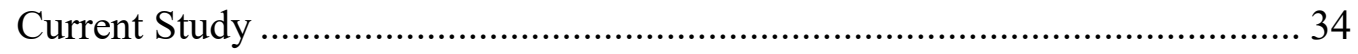

Research Questions .............................................................................. 34

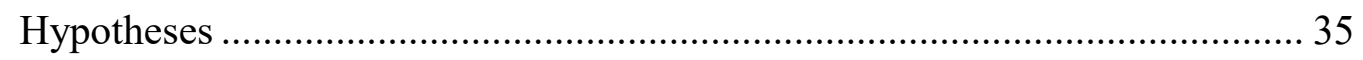




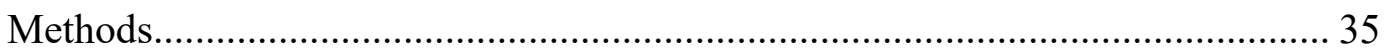

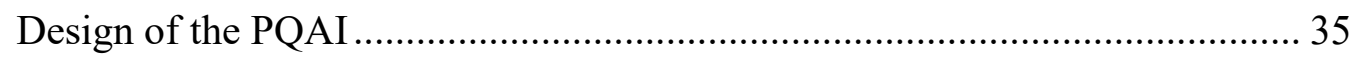

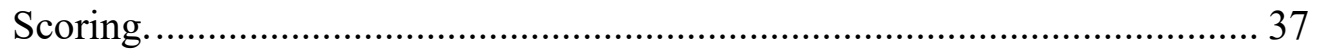

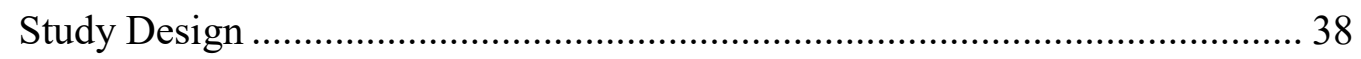

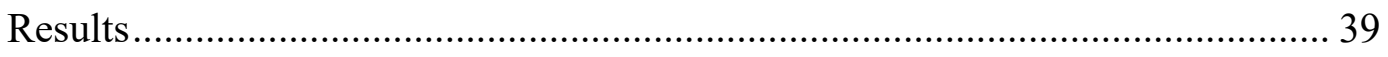

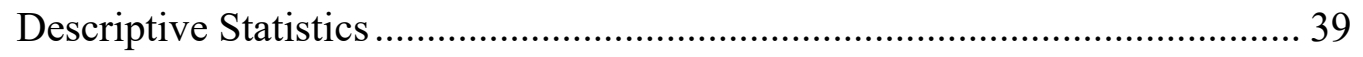

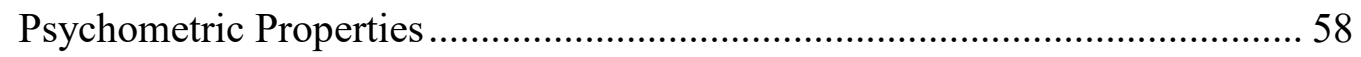

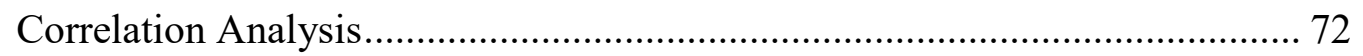

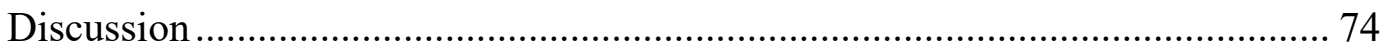

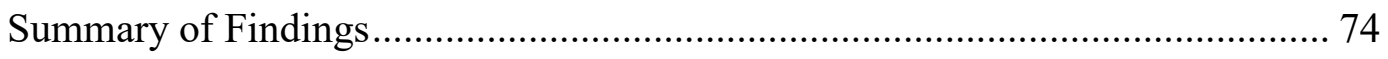

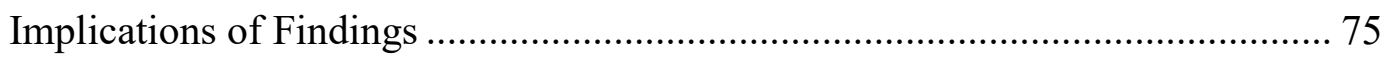

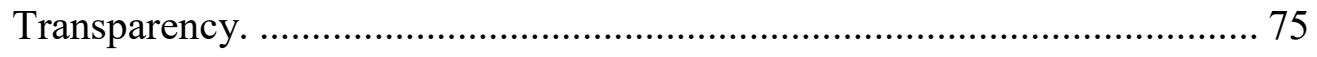

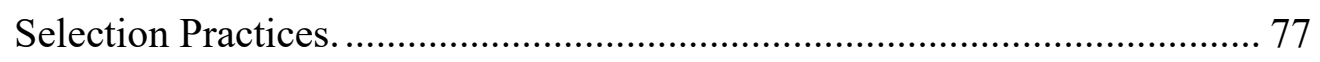

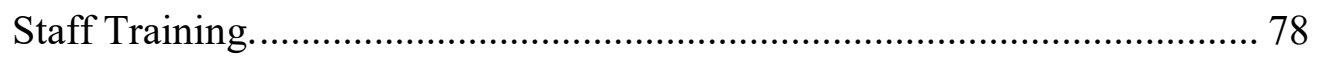

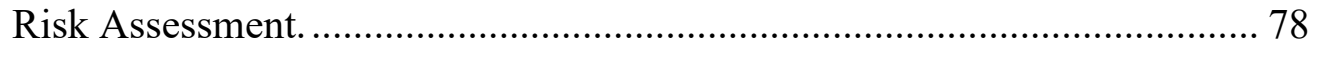

Structured Decision-Making Practices........................................................... 79

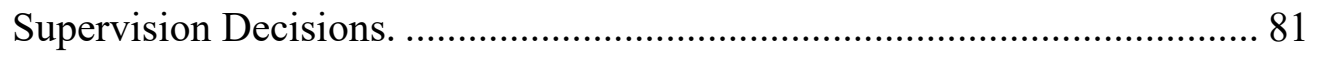

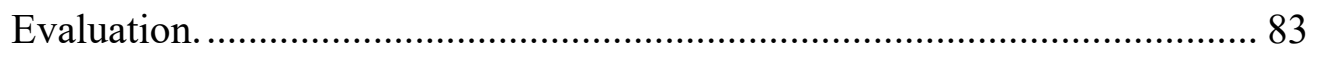

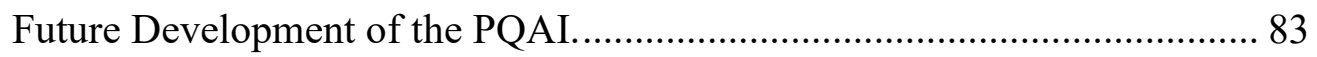

Limitations and Future Directions................................................................. 84

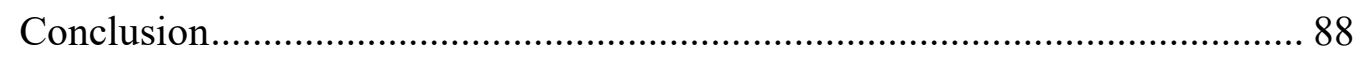

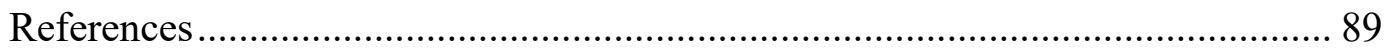




\section{List of Tables}

Table 1: Parole Chair Characteristics 42

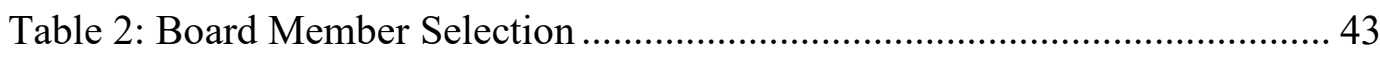

Table 3: Paroling Authority Training ................................................................ 46

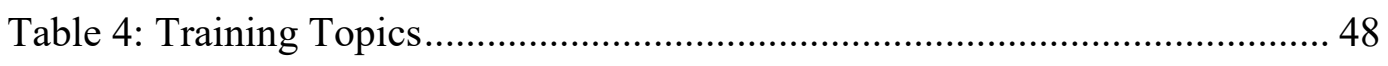

Table 5: Initial Parole Release Decision Factors .................................................... 51

Table 6: Specialized Risk Assessment Instruments............................................... 54

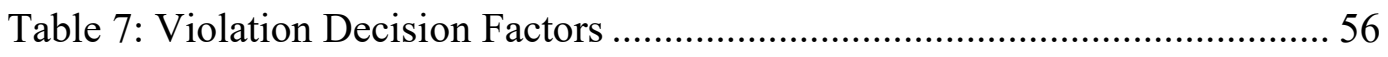

Table 8: Contents of Recidivism Database …………….................................... 57

Table 9: Item Statements of the Mission/Vision Subscale of the PQAI................ 60

Table 10: Item Statements of the Organizational Structure Subscale of the PQAI

Table 11: Item Statements of the Staff Training Subscale of the PQAI............... 63

Table 12: Item Statements of the Decision-Making Process Subscale of the PQAI

Table 13: Item Statements of the Risk Assessment Subscale of the PQAI 67

Table 14: Item Statements of the Violation Decision Process Subscale of the

PQAI . 68

Table 15: Item Statements of the Evaluation Subscale of the PQAI

Table 16: Distribution of the Original PQAI in comparison to the Reduced PQAI 
Table 17: Bivariate Correlations among Original PQAI \& Percentage of

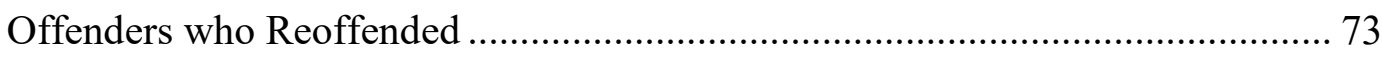

Table 18: Bivariate Correlations among Reduced PQAI \& Percentage of

Offenders who Reoffended 


\section{List of Appendices}

Appendix A - Parole Quality Assurance Inventory ............................................ 110

Appendix B - Parole Quality Assurance Inventory: Reduced Items................... 140 


\section{Development and Validation of a Parole Quality Assurance Inventory}

On July 23, 2007, Joshua Komisarjevksy and Steven Hayes, two Connecticut parolees, committed a home invasion while the family was asleep, resulting in the violent sexual assault and deaths of the mother and two daughters, as well as, the brutal assault of the father (The Associated Press, 2007). This crime sent shockwaves across the country and led many to question the validity of parole. The resulting political backlash to this crime resulted in the state Governor immediately ceasing all paroles and establishing a special task force to examine the state parole practices (Paparozzi \& Caplan, 2009). This particular event, while rare, illustrates the difficulties facing paroling authorities. Time passes between the parole release decision and the offender outcome becoming known, either the expiration of sentence or a community failure. There are a multitude of reasons why an offender may fail within the community that are outside of the paroling authority's control (e.g., deterioration of community support, changes in dynamic risk) which do not necessarily invalidate the parole decision. Hence, judging the efficacy of paroling authorities based solely on the offender outcomes of parolees, while important, is not necessarily ideal. An alternative and perhaps superior method of evaluating paroling authority performance is to examine the quality of their parole decision-making. Increasingly, research is examining ways in which paroling authorities can improve parole fidelity in order to improve rigour and to insulate the organization in the event of community failures (Burke, 2011; Campbell, 2008; Carter, 2011).

While there has been an effort by the criminal justice community to compile targets and supervision strategies intended to enhance parole performance and outcomes, to date there has been no standardized and validated assessment of evidence-based 
practices in parole. The current project is an attempt to operationalize what is known about evidence-based practice in parole, as well as, to examine aspects of paroling authorities and how they function in order to better define high quality paroling organizations. It is hoped that the results of this project contribute to the understanding of the relationship between evidence-based practice and parole outcomes.

Paroling authorities play a critical role in the criminal justice system. They are responsible for deciding which offenders obtain release and when; the setting of release conditions; and, determining if technical violations of parole warrant termination and reimprisonment. By releasing offenders when they are at an acceptable risk of reoffending (or their risk can be effectively managed within the community) and by setting reasonable parole conditions that are focused on the offender's risk and needs, paroling authorities can enhance public safety and reduce prison costs. Benefits of parole decision-making can be seen as parolees reoffend at much lower rates $(38 \%)$ than those who are released without supervision at the completion of their sentence (55\%) (PEW Charitable Trusts, 2013). As well paroling authorities must use resources judiciously; when parole violations occur, paroling authorities must concurrently respond to the seriousness of the violation, the offender's level of risk, and any situational risks factors such that the risk of future violations is minimized (Burke, 2011).

Parole can be best defined as a period of conditional supervised release in the community following a prison term; it includes offenders released through discretionary or statutory supervised release (Bonczar \& Maruschak, 2013). It is important to distinguish the difference between statutory release and parole. The former involves the release of offenders who have served a legislated portion of their sentence (e.g., two 
thirds in Canada). It is not a decision made by the paroling authority; however the paroling authority can set conditions on the offender, including residing at a halfway house, in order to manage the risk of further criminal behavior. Parole is a discretionary decision to release an offender to safely complete their sentence in the community under supervision. It is also essential to differentiate how parole differs from probation. While parole is community supervision after a period of incarceration, probation is a period of court-ordered community supervision as an alternative to incarceration (Bonczar \& Maruschak, 2013). In short, paroling authorities can determine whether an eligible offender will be granted parole as well as what conditions will be imposed upon the individual's release. Paroling authorities often also have periphery functions such as making decisions on pardons, parole violations and clemency (Parole Board of Canada, 2013b).

A common criticism of parole is that it functions as a shortening of an offender's sentence (McIntosh, 2003), however, this is not actually the case. Parole simply allows an offender to return into the community with additional structure and support until their sentence expires.

Parole is a popular release option internationally. Within the United States, 48 states have paroling authorities in addition to post-release supervision programs in place (Paparozzi \& Caplan, 2009). Likewise, within Canada, the Parole Board of Canada 
makes decisions on federal offenders as well as for provinces and territories that do not have their own parole board ${ }^{1}$ (Parole Board of Canada, 2009).

\section{Offenders Under Supervision}

In 2013/14, there were 7,477 federally-sentenced adult offenders in Canada who were under some sort of community supervision ${ }^{2}$. Of these, 4,450 offenders were on parole which is a slight increase than the previous year (Public Safety Canada Portfolio Corrections Statistics Committee, 2014). When examining American trends, in 2013, there were 4,751,400 adult offenders who were under some sort of community supervision (this number includes both probationers and parolees), which is equal to one in fifty-one Americans. Of these, 853,200 adults were part of the parole population, ${ }^{3}$ which increased by 2,000 adult offenders from the previous year (Glaze \& Kaeble, 2014). In fact, when examining long term trends, the number of offenders on community supervision in the U.S. has increased by an average $1.3 \%$ annually from 2000 to 2012 (Herberman \& Bonczar, 2015).

When examining successful completions of parole supervision in the U.S. during $2013,61 \%$ of offenders completed their supervision or obtained an early discharge; however, $35 \%$ of offender returned to incarceration, absconded, or had another unsatisfactory ending (Herberman \& Bonczar, 2015). Canadian trends are more optimistic, with $85 \%$ of federal parolees successfully completing their supervision

\footnotetext{
${ }^{1}$ Only the provinces of Ontario, British Columbia and Quebec have provincial parole boards (Parole Board of Canada, 2009).

2 This number includes those being actively supervised on day parole, full parole, statutory release, and on a long term supervision order (Public Safety Canada Portfolio Corrections Statistics Committee, 2013).

${ }^{3}$ This figure includes mandatory release, military parole, and special parole. (Bonczar \& Maruschak, 2013).
} 
period $^{4}$ (Public Safety Canada Portfolio Corrections Statistics Committee, 2014). Overall, the large number of offenders that do not successfully complete their supervision can often result in thousands of new crimes, higher rates of victimization, and increased resources being spent on the associated costs of crime (Carter, 2011).

\section{Public Opinion}

Public opinion polls show that trust in the criminal justice system is low (Center for Effective Public Policy, Pretrial Justice Institute, The Justice Management Institute, and The Carey Group, 2010; Latimer \& Desjardins, 2007; The Parole Board of Canada, 2013b; Roberts, Nuffield, \& Hann, 2000). It appears that public confidence decreases as one progresses through the criminal justice process. The public is more confident, for example, that police are arresting the guilty person and that the courts will render an appropriate guilty verdict; whereas they are less confident those offenders are being rehabilitated and that parole boards are releasing appropriate offenders (Latimer \& Desjardins, 2007). Therefore, it is unsurprising that $80 \%$ of the public feels that the current rates of recidivism are unacceptable (Center for Effective Public Policy, Pretrial Justice Institute, The Justice Management Institute, and The Carey Group, 2010; Latimer \& Desjardins, 2007). This lack of confidence can further be seen in the recently passed, although controversial, Bill C-10; which aims to protect the public through, in part, placing greater importance on victim involvement and reducing the use of conditional sentences (Bill C-10, 2012). Clearly stakeholders feel that the current state of the criminal

\footnotetext{
${ }^{4}$ It is important to note that Canadian and American statistics are not directly comparable because of differences in follow-up time.
} 
justice system is unsatisfactory, and thus changes to the system should be made in order to improve public confidence.

The high number of incarcerated offenders, and those who continue to reoffend while under supervision, in the U.S. and Canada is clearly a problem. An important consideration is whether parole is an underlying problem or a potential solution. It is imperative to determine whether paroling authorities have the capabilities to make highquality decisions that permit the early and safe release of individuals, thereby reducing incarceration costs and contributing to offender rehabilitation. Such decisions should also prevent future crime and victimization. Hence, is parole an effective evidence-based practice or an overly optimistic aspect of the criminal justice system which should be eliminated?

Paroling authorities have answered criticisms by introducing more empiricallyinformed practices into their decisions. Parole research has been examining what paroling authorities can do to reduce recidivism rates for the approximately $95 \%$ of offenders who will inevitably be released into the community (Burke, 2011; Caplan, 2007; Hughes \& Wilson, 2003; PEW Charitable Trusts, 2013), but this research has mainly focused on the factors that paroling authorities report taking into account when making release decisions (Caplan, 2007; Gobeil, 2006; Gobeil \& Serin, 2009). Increasingly, however, paroling authorities are looking for further ways to improve their decisions, beyond merely listing the factors they are taking into account. These aims can be reflected in the ten targets of the National Parole Resource Center's self-assessment toolkit; it defines ways in which paroling authorities can achieve their goals for quality parole decisions more successfully (National Parole Resource Center, 2013). The ten targets are as follows: 
1. Use good, empirically-based actuarial tools to assess risk and criminogenic needs of offenders

2. Develop and use clear, evidence-based, policy-driven decision-making tools, policies, and guidelines that reflect the full range of a paroling authority's concerns (e.g., punishment, victim issues, community safety, etc.).

3. Maintain meaningful partnerships with institutional corrections and community supervision (and others) to encourage a seamless transition process and the availability of sound, evidence-based programs.

4. Use their influence and leverage to target institutional and community resources to mid- and high-risk offenders to address their criminogenic needs.

5. Consider for release at the earliest stage possible - in light of statutes and other sentencing interests - offenders assessed as low risk.

6. Use the parole interview/hearing/review process as an opportunity to - among other goals - enhance offender motivation to change.

7. Fashion condition setting policy to minimize requirements on low risk offenders, and target conditions to criminogenic needs of medium and high-risk offenders.

8. Develop policy-driven, evidence-informed responses to parole violations that incorporate considerations of risk, criminogenic need and severity, assure evenhanded treatment of violators, and utilize resources wisely.

9. Develop and strengthen case-level decision making skills/capacities in these areas.

10. Develop and strengthen agency level policy making, strategic management and performance measurement skills/capacities. 
These targets have not been empirically tested. The current research project will expand on and code these factors for validation while systematically collecting descriptive and outcome data for comparison across paroling authorities.

\section{Evidence Based Policy and Practice}

Evidence-based policy and practice (EBP) emphasizes that public policy, practice, and decisions should reflect the most recent and empirically-sound, scientific evidence that is available at the time in order to make the most effective and efficient use of financial resources (Campbell, 2008; Carter, 2011). This is a term that originated over forty years ago in the medical field when Cochrane (1972) postulated that empirical research should be utilized when deciding how to use limited medical resources; arguing research-based policy and practice would be more likely to yield more desirable and reliable results. Within the criminal justice field, EBP is being used in many areas such as; police suspect lineups (Hinz \& Pezdek, 2001), jury selection methods (Fukurai, 1996), correctional treatment interventions (Andrews \& Bonta, 2010; Porporino, Robinson, Millson, \& Weekes, 2002), and parole release (Anderson, Shumacker, \& Anderson, 1991). Through EBP, these areas can yield more effective outcomes by making the best use of public resources to reduce future crime and victimization (Carter, 2011).

When applying EBP to parole decision-making, it is important to first examine what research has demonstrated to be effective, and then to use these results to inform decision-making in practice. There are many areas of parole decision-making in which utilizing EBP would be beneficial. These range from determining offender suitability for release, consideration of what factors should be taken into account during the decision- 
making process, and appropriate board member selection and training of board members (Campbell, 2008).

\section{The Rationale for Embracing Evidence-Based Approaches}

Accuracy. Given the high rates of unsuccessful parole completions (Herberman \& Bonczar, 2015), it is essential that paroling authorities increase the accuracy of their parole decisions. It is encouraging that a large area of programming research has demonstrated between a 10 and $30 \%$ reduction in recidivism if evidence-based knowledge is harnessed in the criminal justice system with precision (Andrews \& Bonta, 1998, 2006, 2007; Andrews et al., 1990; Aos, Miller, \& Drake, 2006; Gendreau \& Goggin, 1996; Landenberger \& Lipsey, 2005). Corrections research has increased our understanding of what works for correctional programming, but the current issue is how to implement what works in regards to an individual offender's rehabilitation. One of the areas in which evidence-based knowledge can be better utilized is that of parole practices.

When offenders meet the eligibility requirements to apply for parole (this is often when they have served a predetermined portion of their sentence, Parole Board of Canada, 2010b), paroling authorities are in the position to determine whether the offender should be released and what parole conditions should be placed upon the offender in order to manage his/her risk of criminal behaviour in the community. While research has shown that risk assessment instruments are able to predict future criminal behaviour with some precision (e.g., Yang, Wong, and Coid, (2010) found that for some of the most popular risk assessments, AUC values ranged from .56 to .71 ) a risk score is not a substitute for parole decision due to legislative requirements (Corrections and Conditional Release Act, 1992). Nonetheless, parole decision making should be grounded 
with an empirically-based risk score. Greater parole decision-making accuracy can be developed by implementing empirically-supported practices involved in areas such as, what factors are considered when making decisions (Caplan, 2007; Serin, 2007a), risk assessment (Campbell, French, \& Gendreau, 2009), offender treatment (Andrews \& Dowden, 2006), and evaluating genuine offender change (Serin \& Lloyd, 2009).

It is important for paroling authorities to be continually aware of new and emerging research so they can be improving their policies and practices. Emerging research in the use of parole conditions, for example, may aid paroling authorities when making release decisions (Serin, Wardrop, \& Mausser, in preparation; Travis \& Stacey, 2010). This heightened understanding and application can potentially lead to decreases in crime and future victimization as well as an increased parole grant rate (Public Safety Canada Portfolio Corrections Statistics Committee, 2014).

Furthermore, there is a financial incentive to increase the accuracy of parole decisions. With the large number of false positives (i.e., offenders who are incorrectly assessed as likely to reoffend.) (Herberman \& Bonczar, 2015), the costs associated with recidivism are immense. With the average taxpayer cost per offender in incarceration being $\$ 31,286$ US annually (Henrichson \& Delaney, 2012), if we were able to reduce recidivism rates by just $5 \%$ we would save $\$ 250,483,537$ a year.

Meets Policy Requirements. According to the Canadian Corrections and Conditional Release Act (CCRA; 1992), the function of parole is "to contribute to the maintenance of a just, peaceful and safe society by means of decisions on the timing and conditions of release that will best facilitate the rehabilitation of offenders and the reintegration into the community as law-abiding citizens." It later states that the paroling 
authority can grant parole to an offender if two stipulations are met: "(a) the offender will not, by reoffending, present an undue risk to society before the expiration according to law of the sentence the offender is serving; and (b) the release of the offender will contribute to the protection of society by facilitating the reintegration of the offender into society as a law-abiding citizen" (CCRA. 1992, C.20, s.102). This concept is further exemplified in Bill C-10 which places paramount importance on public safety (Bill C-10, 2012). This legislation is operationalized Section 2.1 of the Parole Board of Canada Policy Manual (2014a) which specifies how paroling authorities should being making these decisions and what factors should be taken under consideration. Canadian parole policy emphasizes the use of EBP through using validated and offender-specific risk assessment instruments, and considering factors that have been known to be connected to criminal behaviour (e.g., criminal history, self-control, correctional programming, institutional/community behaviour, offender change, and release plan; Parole Board of Canada, 2014a; Serin \& Gobeil, in preparation). As such, this parole decision-making framework defines a "quality" parole decision. Encouragingly, Campbell (2008) suggests that when policy and evidence-based decision models are used, decision-makers will be consistent with the mission of the paroling authority which will lead to more reliable and accurate decisions being made. This can be reflected in Canadian parole trends as successful completions of parole have been steadily increasing over the years with over $80 \%$ of federal day paroles having been successfully completed in 2012 (Public Safety Canada Portfolio Corrections Statistics Committee, 2013)

Transparency. In the past, research has shown that incarcerated offenders possess very little knowledge regarding the parole process, including what factors are 
taken into account when making a decision, and therefore, have difficulty understanding parole decisions (Hawkins, 1973). In some jurisdictions, these decisions can often be made without the offender present and no/very brief explanation given as to why or why not parole was granted. Unsurprisingly, then, offenders can often have low confidence in the paroling authority and view the decisions as being arbitrary and inequitable (Hawkins, 1973). West-Smith, Pogrebin, and Poole (2000), found that when there was a discrepancy in what offenders thought was taken in account versus the actual factors that paroling authorities utilize when making release decisions, they were more likely to be confused, frustrated, and these feelings would fuel fear and resentment in the prison population as a whole. These feelings are unsurprising given the large number of offenders who experience feelings of unfairness and lack of trust in general within the prison system (Liebling, 2004). Such views might also undermine offenders' response to parole supervision.

Defining a quality parole decision is clearly critical. Further, communicating its development, validity and process to stakeholders (e.g., offenders, the public, victims, legislators, etc.) could limit paroling authorities' vulnerability towards inevitable negative offender outcomes and resultant criticisms. This is especially true if it can be shown the initial decision appeared sound and that events beyond the paroling authorities' control resulted in offender failure (e.g., deterioration in community support, increase in dynamic risk factors, etc.). In comparison to unstructured clinical judgement (i.e., when paroling authorities make decisions solely based on personal judgement and experience), decisionmaking that utilizes empirical evidence is much less ambiguous and more defensible (Campbell, 2008; Carter, 2011). More transparent decision-making, along with standards 
for parole decisions should indicate that parole is neither an unfair or arbitrary process, thereby increasing public support for parole (Burke, 2011).

\section{Effective and Efficient Parole Decision-making}

Emerging research (Andrews \& Bonta, 2007; Andrews, Bonta, \& Wormith, 2010; Burke \& Tonry, 2006; Campbell, French, \& Gendreau, 2009; Friendship, Mann, \& Beech, 2003; Garcia-Mansilla, Rosenfeld, \& Cruise, 2011) is producing insight about how the criminal justice system can prevent future crime and victimization, and better allocate valuable taxpayer money. Advances in offender risk assessment (Campbell, French, \& Gendreau, 2009; Yang, Wong, \& Coid, 2010), offender programming (Aos, Miller, \& Drake, 2006; Gendreau \& Goggin, 1996), parole decision-making (Caplan, 2007; Serin, 2004), and risk management (Brown, St. Armand, \& Zamble, 2009; Campbell, 2008) allows paroling authorities to better determine which offenders are best prepared to be released. Upon release, imposing appropriate parole conditions should aid in managing their risk (Serin \& Mausser, 2012). By strengthening their decision-making regarding offender risk, setting of conditions, and responding to violations, paroling authorities can maintain practices that have shown to be effective and discontinue those that are proven ineffective (Burke, 2011).

Moreover, other aspects of a paroling authority might also impact performance in terms of effectiveness (e.g., grant rate, parole violation rate, recidivism rate, etc.) and efficacy (e.g., time per decision, use of interviews, offender representation, etc.). Areas to examine are: (a) mission/vision of the paroling authority, (b) its organizational structure (c) training of staff, (d) decision-making and violation process, (e) assessment of offender 
risk, and (f) the internal evaluation practices of the organization. These areas will now be discussed in greater detail.

Vision/Mission. Paroling authorities draw their meaning and authority from policies and statutes that are delineated by government legislature (for an example, see Parole Board of Canada, 2014a). These statutes define the organization of the paroling authority, and the decision-making process to be undertaken when making release decisions. Nevertheless, these statutes and policies often leave much for the paroling authorities to interpret. Some paroling authorities deal with this issue by developing vision (i.e., a statement that clearly identifies the organization's proposed direction) and/or mission statements (i.e., a statement that clearly indicates how the organization will operate in order to achieve a broad objective) in order to provide greater direction to decision-makers (Campbell, 2008).

Vision and mission statements are beneficial as they set underlying values that direct paroling authorities in their decision-making. Vision/mission statements that clearly articulate the objectives of the paroling authority aid in fostering trust with community members, the media, and legislators (Campbell, 2008; Stroker, 2010, 2011). If paroling authorities do not have vision/mission statements, decision-makers may fixate on individual and sensational cases without considering the broader context. This could possibly lead to paroling authorities allowing personal perspectives to influence decisions; decisions about similar offender circumstances would then have very different outcomes depending on the decision maker. Such decision variability has been demonstrated in mock parole decision-making research (Gobeil \& Serin, 2009) and alluded to as a reality in some jurisdictions (Paparozzi \& Caplan, 2009). Notably such 
intrapersonal variability is fundamentally unfair to the offender as well as society, as it risks contributing to the preservation of inappropriate biases (e.g., gender or racial biases) and decreases decision accuracy (Stroker, 2010, 2011).

It is important to note that often times having particular goals for an organization does not necessarily mean that it will achieve these goals. Having an overarching vision statement written on a wall or in a policy manual does not always translate into immediate and tangible results (Mullane, 2002). This is where having a strategic plan can be helpful. Stroker (2010) suggests that a strategic plan be made up of three elements; firstly, it ascertains where the organization stands in terms of its goals. Secondly, it identifies impediments that are standing in the way of the organization achieving its goals, and thirdly, it establishes future steps that the organization can take in order to achieve its goals. One can logically see that regularly reviewing an organization's strategic plan could better motivate employees to strive towards achieving their organizational goals.

Consequently, performance should be enhanced when paroling authorities develop mission and vision statements, as well as having a strategic plan in order to strengthen the consistency of parole decisions. Furthermore, paroling authorities should regularly examine performance indicators to determine whether the organization is meeting its goals of improving offender outcomes while maintaining community safety. By regularly examining existing processes, paroling authorities will be better able to recognize problems that may impede their performance, as well as ways to improve decision-making and move the organization in a more positive direction (Campbell, 2008). 
Organizational Structure. Ideally, paroling authorities should be structured in a way that optimizes their ability to make effective paroling decisions. This could be achieved by defining board member competencies and selecting such skilled individuals for paroling authority positions (Campbell, 2008). A paroling authority chair would then ensure that board members are competent in all necessary areas prior to making decisions.

It is concerning to see that the board member selection process, all too often, gives new appointments on the basis of political affiliation; $85 \%$ of all U.S. board members were being appointed by the state governor (Kinnevy \& Caplan, 2008a). Paparozzi and Caplan (2009) also conducted a comprehensive survey of American paroling authorities to examine the organizational structure and uncovered a number of interesting findings regarding the appointment process. Board member selection was remarkably political, with the majority of appointments being by the state governor and only four states advertising board openings to the public. When examining the board member requirements, the majority of U.S. states had unclear or non-existent educational qualifications and work experience requirements for the appointments. This is particularly alarming given the difficult ethical and scientific issues associated with release decisions. It is further troubling that, at this point, there has been very little discussion or research regarding board member selection and hiring (Paparozzi \& Caplan, 2009).

Fortunately, paroling authorities are beginning to realise that they should improve hiring practices. For example, in Canada, potential board member candidates are subjected to specific selection criteria. Possible candidates must have a university degree 
in the human sciences (or an acceptable amount of work-related experience), and a minimum of five years of experience in decision-making and/or the criminal justice field. Individuals are assessed through written exams and interviews in order to evaluate their knowledge and skills that are essential to be an effective parole board member (Parole Board of Canada, 2010a). Expectedly, through more advanced hiring practices, the most suitable individuals will be selected and whose decisions reflect transparency and accuracy.

Another area of concern facing board member selection is whether the demographics of the paroling authority are similar to the jurisdiction that they serve. It is important for the paroling authority to be from diverse backgrounds similar to the jurisdiction in which they work in so that they can accurately represent the values of the community (CCRA S.C. 1992, c.20). When a disparity of demographics exists, paroling authorities may risk losing credibility with the community in which they serve.

Staff Training. It is important that board chairs and members receive the necessary training required to successfully perform their duties. This should occur both externally (e.g., outside conferences and workshops) and internally (e.g., regular staff meetings to discuss policy changes, etc.; Campbell, 2008). There are a number of areas that should be covered in training such as risk assessment instruments, decision guidelines, correctional intervention, offender needs, and offender change.

Given the wide range of offenders with whom board members will interact, it is important they be well versed in the unique offender needs associated with distinct offender subgroups (e.g., sex offenders, domestic violence offenders, women offenders, and juvenile offenders) and particular special offender issues (e.g., mental health issues, 
substance abuse issues, and age-related issues). When making decisions, it is common for paroling authorities to have an offender who exhibits a combination of these factors (e.g., a sex offender with substance issues; Burke, 2011), so decision-makers must also understand interactions among risk factors. Often, specific types of offenders would benefit from special conditions (e.g., criminogenic programming) for managing risk in the community (Burke, Giguere, Gillian, \& Center for Effective Public Policy, 2011; Johnson, Friedmann, Green, Harrington, \& Taxman, 2011).

The Parole Board of Canada (2013a), as well as Campbell (2008), have developed a number of Board member competencies that are believed to be required in order to be successful in parole decision-making. They include competencies such as, adaptability, teamwork, interpersonal skills, time management, sensitivity to diversity, values and ethics, oral communication, written expression, and reading comprehension. At this point in time, there has been no research into whether current board member training methods significantly improve these types of competencies; however, this is an optimal area for further exploration.

Research such as that conducted by Gobeil (2012) shows the difficulty in providing proper criminal justice training. This research examined the effects of structured decision-making guideline and risk assessment training on parole officer recommendations, finding that parole officers perceived the training quite positively. However, this did not translate into significant behavioural change, in that post-training parole reports did not increase the amount of risk relevance factors they contained. There were many possible explanations for these findings, one of which was the complaint by parole officers that there was too little time to sufficiently cover all the necessary 
information and to practice the skills they learned, or in more technical terms, trainees were not given the correct dosage of training. The concept of "dosage-response" (i.e., the relationship between the extent of training and the extent of observed outcome improvement; Valentine, Gottlieb, Keel, Friffith, \& Ruthazer, 1988) seems relevant for board member training.

Luckily, paroling authorities in the U.S. have a number training opportunities afforded to them by the National Institute of Corrections (NIC) and The Association of Paroling Authorities International (APAI). These cover a wide range of training topics (e.g., decision-making, women offenders, evidence-based practices, and leadership skills, etc.) in classroom, online, and blended formats and this training can be utilized by both new and experienced parole board members (National Institute of Corrections, 2014).

Likewise, in the Canadian context, the Parole Board of Canada places great importance on training board members in evidence-based practices. This is done through the implementation of a collaborative and coherent program which guides training for all board members to affirm that specific needs are being met, as well as; the development of learning activities which are associated with the established board member competencies determined to be essential for successful parole decision-making (Parole Board of Canada, 2014b).

Decision-Making and Violation Process. When paroling authorities are preparing to make a decision in regards to offender release or revocation there is a considerable amount of information that must be reviewed. Often this includes looking at the offender's institutional and community behaviour, participation in rehabilitative programming, criminal history, and victim impact statements. It is essential that paroling 
authorities are afforded sufficient time to gain a comprehensive picture of each offender's situation prior to making a decision (Campbell, 2008). The number of cases that are heard per day by paroling authorities can range considerably, often being anywhere from 4 to 6 in Canada (PBC, personal communication, September 17, 2014) to greater than 40 a day in some U.S. states (O’Leary \& Nuffield, 1973).

While some paroling authorities have no interaction with the offender and base their decisions purely on the offender's case file, the vast majority are able to have a faceto-face offender hearing at the time of consideration (Kinnevy \& Caplan, 2008b; O'Leary $\&$ Nuffield, 1973). The hearing can be a good opportunity to gather additional facts, verify information, and learn about the offender's perspective, among other things. The offender hearing is particularly beneficial as it humanizes the offender, allows paroling authorities to provide feedback and hopefully motivates the offender to either start or continue to change in a positive direction (Campbell, 2008; Stroker, 2010). By involving the offender in the decision-making process, they will feel as though they are contributing in some way, further legitimizing the process in their eyes (Hawkins, 1973).

Paroling authorities' decisions require numerous factors be taken into account, all while balancing offender rights and community safety. Ideally government statutes and policies dictate what factors are to be taken into account (for an example see Parole Board of Canada, 2014a), however, research has shown that often extralegal factors (e.g., race, socioeconomic factors, etc.) are also considered (Lytle, 2013). Numerous researchers have found that extra-legal factors impact the degree of arbitrariness of nonguided criminal justice decisions. Individuals who belong to a minority racial group and/or lower socioeconomic status have been shown to be required higher bond amounts 
(Farnworth \& Horan, 1980), are less likely to obtain bail (Lizotte, 1978), are less likely to obtain probation (Unnever, Frazier, \& Henretta, 1980), are at an increased likelihood of being found guilty (Farnworth \& Horan, 1980), are rated as being more guilty by mock jurists (Pfeifer \& Ogloff, 1991), are more likely to receive longer prison sentences (Farnworth \& Horan, 1980) and are more likely to wait longer to be granted parole (Huebner \& Bynum, 2008).

It is also essential to examine the research evidence in regards to how factors are taken into account and their weighting in the decision-making process. Samra (1997) found that decision-makers often take into account the same factors/content areas; however, the weight they will place on criteria can differ. More specifically, decisionmakers who favour parole weigh rehabilitative criteria (e.g., participating/benefiting from correctional programming, proposed release plan) more heavily than those opposing parole, with the latter putting more weight on punishment-oriented concerns (e.g., the offender's attitude in regards to their criminal and prison behaviour). These types of attitudes have been seen across the criminal justice system by caseworkers (Holland \& Holt, 1978), and case-management officers (Samra-Grewal, Pfeifer, \& Ogloff, 1997) potentially influencing decisions throughout the criminal justice system. Hence, in the absence of structured guidelines, decision-makers will weight factors differently (Gottfredson \& Ballard, 1966; Gobeil \& Serin, 2009; Hoffman, 1972; Sacks, 1974; Scott, 1974; Rogers \& Hayner, 1968), leading to inconsistency in decision-making.

All this to say, given the complexity of parole decision-making, it appears that unstructured decision-making is problematic and having empirically validated, structured decision guidelines would be beneficial as they inform paroling authorities on what 
factors should be used and their appropriate weight. Guidelines provide a method and consistency to structure decision-making, as well as limit the amount of discretion afforded to decision-makers (Burke, 2011). The Structured Release Decision Making Framework (Serin, 2004) is a good example of parole guidelines that inform the paroling authority in terms of the factors to be taken into account. This framework has been found to positively aid paroling authorities in making more accurate decisions (Serin \& Gobeil, in preparation). Another option available to paroling authorities is a parole matrix; developed to address concerns regarding perceived arbitrariness and unfettered board member discretion in parole release decisions (Taylor, 1979). When the matrix flags predetermined factors (e.g., crime severity and risk) a recommended decision will be provided to the paroling authority (Gottfredson, 1978). Parole matrices were formulated in order to aid decision-making, however, Pogrebin and colleagues (1986) found that board members did not like using matrices and would vote not to adopt their use. The researchers speculated that this may have been because parole board members felt that the matrix structured their decisions in a way that there was not enough individual discretion allowed. Even though the structured decision matrix may not have been initially popular, some states, such as Colorado, Pennsylvania, and Maryland have implemented similar tools (Colorado State Board of Parole, 2013; Campbell, 2008). Another important decision that paroling authorities have to make is what and how many conditions should be placed on an offender who will be released onto parole. Parole conditions can range considerably in scope and frequency, and are intended to inhibit future criminal behavior and manage offender risk (Barkdull, 1976; Travis \& Stacey, 2010). Examples of common parole conditions are abstaining from criminal 
behavior, substance use, travel restrictions, and finding/maintaining employment (Serin, Wardrop \& Mausser, in preparation). A common belief is that the more conditions you place on the offender, the less likely the offender will be to reoffend and the safer the community will be. However, this is not the case as conditions that are too many, impractical, or excessive will just serve as roadblocks to successful completion of parole (Petersilia, 2001; Travis \& Stacey, 2010). An offender may, for example, have difficulty finding/maintaining employment, attending multiple types of community programming, abstaining from drugs and alcohol, maintaining a curfew, all while attending regular meetings with their parole officer.

In reality, paroling authorities should use parole conditions in order to target criminogenic needs of the offender that need continual attention. For example, a high-risk substance abuse offender should be placed in substance abuse programming whereas a low-risk substance abuse offender should not as this may increase their level of risk (Bourgon \& Armstrong, 2005; Gendreau \& Goggin, 1996; Lloyd, Hanby, \& Serin, 2014). Consequently, if a high risk offender is adjusting well to community supervision and intervention over an extended period of time, he or she may be reclassified to have less supervision and fewer conditions to meet (Campbell, 2008).

It appears that although some more stringent conditions (such as placement in a residential substance abuse program) may help address particular criminogenic factors and may reduce the likelihood of recidivism for higher risk offenders, these conditions may actually contribute to increased recidivism for lower risk offenders (Bonta, WallaceCapretta, \& Rooney, 2000; Lowenkamp \& Latessa, 2005). Researchers hypothesize this may occur as low risk offenders (who experience low levels of pro-criminal 
attitudes/traits) are placed in high intensity programming with high-risk offenders, they are exposed to higher levels of criminal thinking (Bonta, Wallace-Capretta, \& Rooney, 2000). In this manner, treatment becomes iatrogenic.

More recent research has focused on the relationship that treatment dosage has with offenders' risk level on recidivism (Makarios, Sperber, \& Latessa, 2014). Findings show that offender risk moderates the relationship between the dosage of treatment and recidivism, but non-linearly. For both low/moderate risk and moderate risk offenders, initial increase in treatment dosage is related with decreases in recidivism; however, further increase in dosage is related to increases in recidivism. These findings further reinforce the importance of paroling authorities to account for offender risk when making release decisions.

The notion that more is better when it comes to imposing conditions on parolees is simply inaccurate. Control and punishment-oriented conditions (such as curfew, home detention, or intensive supervision), without treatment, appear to have little positive effect on reducing recidivism (Aos, Phipps, Barnoski \& Lieb, 2001). Conditions should focus instead on individually determined criminogenic factors in that addressing such factors appears to contribute significantly to the likelihood of recidivism.

Furthermore, when decisions are made to either grant or reject parole, it is important that paroling authorities communicate with the offender as to what that decision is and why. This type of procedure allows the paroling authority to justify their decision, remove ambiguity from their decision, and provide feedback to the offender on how they should improve themselves (Campbell, 2008). Immediately informing the offender of the parole decision and detailing the reasons behind it, a practice that occurs 
infrequently (Hawkins, 1973), allows for a sense of fair-mindedness and transparency in the parole system. This promotes the perception that the parole board does not make decisions based on arbitrary factors. Hawkins (1973) postulates that by promoting transparency and fairness in the parole system, offenders will have decreased feelings of oppression and injustice, and of increased accountability and trust in the criminal justice system. O'Leary and Nuffield's (1973) survey of U.S. paroling authorities found that only 22 of 51 parole jurisdictions had a formal policy that requires paroling authorities to inform the offender about the decision in person at the end of the parole hearing and only 11 of those kept a written record of the reasons behind the decision. It is important to be aware that much of this research is over thirty years old; clearly, this is an area that warrants further scrutiny by current paroling authorities.

Risk Assessment. Increasingly, paroling authorities are incorporating an assessment of an offenders' risk of reoffending to anchor their decision-making process. In the past this was done using unstructured clinical judgement where decision-makers utilized their experience and professional judgement of whether an offender was likely to reoffend if granted parole (Bonta, 1996). A serious limitation of this method of assessment is that it allows for personal opinion and bias to cloud judgement and enables for inconsistencies in decisions. Decisions made using unstructured clinical judgement are inaccurate and predict recidivism at chance levels of accuracy (Bengtson \& Långström, 2007). Instead, paroling authorities should be using validated, empiricallybased risk assessment instruments to determine an offender's level of risk.

For three decades efforts to develop actuarial risk instruments using factors or variables that have been shown to correlate with recidivism, have flourished and found to 
be predictive of recidivism (Yang, Wong, \& Coid, 2010). Actuarial risk assessments were first developed to include static risk factors (e.g., Violence Risk Appraisal Guide Revised; Harris, Rice, \& Quinsey, 1993). Static risk factors are historical variables that are incapable of change or fluctuation (e.g., age of first arrest, number of prior parole violations, etc.). Static risk instruments greatly outperform unstructured clinical judgement (Bengtson \& Långström, 2007); however, a major drawback of static risk instruments is that they are unchangeable, so they are unable to account for treatment success and risk management endeavours. Increasingly, risk assessment is being seen as not just a crime prediction measure, but a measure that is used for offender management and risk reduction (Burke, 2011; Douglas \& Kropp, 2002). Risk assessment instruments that include dynamic factors (i.e., factors that can be changed over time either through intervention or spontaneously) allow the decision-maker to determine whether an offender's risk of reoffending can be reduced by setting particular parole conditions (e.g., and offender with antisocial attitudes may benefit from cognitive-behavioural programming; Kroner \& Yessine, 2013).

More recent research has been developing risk assessments that incorporate protective factors in addition to static and dynamic factors (e.g. the Dynamic Risk Assessment for Offender Re-entry; Serin, 2007b). Protective risk factors are those that consider positive influences or behaviours that the offender demonstrates and which mitigate risk (Rogers, 2000). Research has shown that scales that include protective factors can predict re-offending moderately well (de Vries Robbé, de Vogel, \& de Spa, 2011; Hoge, Andrews, \& Leschied, 1996; Rennie \& Dolan, 2010). Hence, risk instruments that include dynamic and protective factors should be especially useful for 
paroling authorities as it allows them to inform offenders on ways to reduce their level of risk (e.g., they should work on developing prosocial attitudes) as opposed to static risk instruments (e.g., a paroling authority cannot suggest an offender to go back in time to commit fewer crimes).

Another approach to offender risk assessment, other than actuarial risk assessments, is Structured Professional Judgement (SPJ). This is an approach where clinicians or criminal justice professionals are provided with a scale or list of empiricallybased risk factors to take into account when determining an offender's risk of reoffending (Borum, 1996). Instead of providing a total score, these scales provide board members with risk ratings and recommended courses of action in order to prevent recidivism such as probable scenarios which are likely to occur. This type of assessment is beneficial as it is far more structured in comparison to unstructured clinical judgement and clinicians are obligated to examine a wide range of empirically-based risk factors when making their decisions; however, some professional discretion is permitted. An example of SPJ is the Historical-Clinical-Risk Management-20 (HCR-20; Webster, Douglas, Eaves, \& Hart, 1997). Research has not yet determined whether SPJ is superior over actuarial approaches (Skeem \& Monahan, 2011), though research indicates that SPJ can predict offender outcome with accuracy $(\mathrm{AUC}=0.88)$ (Wilson, Desmarias, Nicholls, Heart, \& Brink, 2013).

When determining what risk assessment instrument should be used, paroling authorities have a plethora of options available to them and it can be difficult to determine which is best. Kroner, Mills, and Reddon (2004) conducted an interesting experiment to try to determine if any particular risk assessment outperformed others by 
taking four different risk assessment instruments (the Psychopathy Checklist-Revised, Level of Service Inventory-Revised, Violence Appraisal Guide, and the General Statistical Information on Recidivism) and comparing the predictive accuracy of them in comparison to four randomly generated risk instruments using the same items. The results suggested that none of the real or randomly constructed instruments predicted community failure significantly better. Yang, Wong, and Coid (2010) found further evidence of this when they examined nine different risk instruments and found that they all predicted violence at better than chance levels, and none of the risk instruments predicted violence significantly better than the others. These results suggest that it does not matter what risk instrument paroling authorities use as long as they use one validated on their offender population.

Another important consideration is for special offender populations to be assessed with specific risk assessment tools as these consider unique risk factors specific to the population. Consequently, a large amount of research has focused on developing risk assessment instruments for specific offender populations; such as, women offenders (Hardyman \& Van Voorhis, 2004; Orbis Partners Inc., 2006; Van Voorhis \& Presser, 2001), sex offenders (Bumby, Carter, Talbot, \& Gilligan, 2007; Friendship, Mann, \& Beech, 2003; Gordon \& Nicholaichuk, 1996; Hanson \& Morton-Bourgon, 2007; Marques, Wideranders, Day, Nelson, \& van Ommeren, 2005), juvenile offenders (Heilbrun, Goldstein, \& Redding, 2005), and mentally disordered offenders (Bonta, Law \& Hanson, 1998; Ho, Thomson, \& Darjee, 2009; Garcia-Mansilla, Rosenfeld, \& Cruise, 2011; Kröner, Stadtland, Eidt, \& Nedopil, 2007; Wilson, Desmarais, Nicholls, Hart, \& Brink, 2013). Popular examples of specialized risk assessment instruments are the HCR- 
20 (Webster, Douglas, Eaves, \& Hart, 1997) and the START (Webster, Martin, Brink, Nicholls, \& Desmarais, 2009) for mentally disordered offenders, the ODARA for intimate partner violence (Hilton, et al. 2004) and the Violence Risk Appraisal Guide (VRAG; Webster, Harris, Rice, Cormier, \& Quinsey, 1994) for violent offenders. When assessing offender risk it is essential to ensure the risk instrument the paroling authority is using has been validated on the local population. For instance, Wright, Clear, and Dickson (1984) found that the Wisconsin risk-assessment instrument predicted recidivism well in offenders from Wisconsin, however, when the use of this instrument expanded it was found that among city of New York offenders, not all the variables included in the instrument predicted future criminal behavior. Desmarais and Singh (2013) recently conducted a meta-analysis examining the research conducted on numerous popular risk assessments; they found that there has been insufficient research examining predictive validity of many risk assessments within specific offender subgroups (e.g., women, African American, and mentally disordered offenders). Accordingly, they caution against their use until further research has occurred.

Evaluation. It is important to have regular outcome evaluations of how well parole authorities are functioning as it provides executives and board members insight into how well the system is working, and possible training targets (Burke \& Tonry, 2006; Campbell, 2008). Areas to evaluate include parolee outcome, training content and satisfaction, decision-making process, and annual statistics about release decisions. This type of evaluation information can inspire board members to look beyond the individual case decisions they make on a daily basis and inform them regarding Boards' impact on the entire criminal justice system. Regular organization evaluations also provide a way to 
defend against outside criticism (Paparozzi \& Demichele, 2008). For example, if a highprofile offender commits a heinous crime while on parole, the media will sensationalize the event. Unfortunately examples of parole successes, such as the $98.4 \%$ of Canadian federal parolees who successfully completed their supervision periods in 2013 (Parole Board of Canada, 2013b), ${ }^{5}$ are rarely acknowledged. Evaluation results are important to share with stakeholders and to better inform the public.

\section{Total Quality Management}

Total Quality Management (TQM) is an organizational framework which is focused on the improvement of organizational processes, and, in turn, increased favorable performance outcomes (Deming, 1986). This is a management strategy that originated in the manufacturing sector, but has extended into areas such as health care (Kaltsounakis, 1995) and education (Venkatraman, 2007). Regardless of where TQM has been utilized, it appears to place a great deal of importance on two concepts: (1) continuous improvement, and (2) the tools and methods used by the organization.

From the criminal justice perspective, this is a framework which could aid paroling authorities in enhancing the fidelity of their organization. The principles of TQM can be loosely adapted for use in paroling authorities and includes some of the relevant evidence-based practices discussed previously. From this perspective, the proposed TQM framework is as follows (adapted from Deming, 1986; Rabih, 1998; Venkatraman, 2007):

\footnotetext{
${ }^{5}$ This is only the percentage of offenders who successfully complete supervision until their warrant expiry date.
} 
1. Leadership: It is essential that senior management (in the parole context this would be the Parole Chair) be involved in creating clear goals and expectations which promote the high-quality performance for which the organization is striving. Organization leaders should also form partnerships with internal and external stakeholders.

2. Continuous Improvement: Organizations should be continually looking for ways to improve the procedures and processes of their organization. In the parole context, this would suggest that paroling authorities should be continually reviewing the latest research in order to adopt evidence-based practices.

3. Staff Participation: Movement towards a quality organization can only occur when staff members are engaged in the change. The organization must invest in the development and training of their employees.

4. Quality Vision: Having a quality vision for your organization is essential for achieving favourable performance outcomes. In the parole context, this is associated with the concept of developing vision/mission statements and having a strategic plan to carry out these goals. Consistency of parole decisions should increase when board members are driven by the same goals.

5. System Perspective: This principle indicates that it is important to develop quality systems which are required to produce quality work. From the parole perspective, this would suggest that paroling authorities should be adopting high-quality evidence-based tools when making decisions as this will lead to 
more consistent and accurate decisions being made (e.g., the Structured Decision Making Framework; Serin, 2004).

6. Management by Fact: The final principle suggests that it is vital to use statistical processes to measure improvements made in quality. Paroling authorities should take that to mean that they should be continually evaluating their performance so that executives and board members have insight into how well the system is working.

\section{Measuring Efficient and Effective Parole Decision-Making}

Parole research to date has mainly examined the factors that paroling authorities report taking into account when making parole decisions (Caplan, 2007; Gobeil, 2006; Gobeil \& Serin, 2009). Increasingly, however, paroling authorities are looking for ways to improve their decisions by introducing more evidence-based policy and practices. Recent developments in EBP in the field of parole have heightened the need for an instrument designed to measure the degree to which paroling authorities incorporate EBP into their organizations. While no scale exists for parole, a similar instrument has been developed to measure the effectiveness of correctional programs, the Correctional Program Assurance Inventory (CPAI; Andrews \& Bonta, 2007).

Correctional Program Assurance Inventory. Considerable research has been conducted regarding the efficacy of correctional programming (Andrews \& Bonta 2007; Aos, Miller, \& Drake, 2006). However, what had been lacking in the criminal justice system was a reliable way to measure the components of effective correctional programs. The Correctional Program Assessment Inventory (CPAI; Gendreau \& Andrews, 1994) is a measure that examines the quality of real-world correctional programs. It assesses eight 
dimensions of programs: (a) organizational culture, (b) program

implementation/maintenance, (c) management/staff characteristics, (d) client risk/need practices, (e) program characteristics, (f) dimensions of core correctional practice, (g) inter-agency communication, and (h) evaluation.

An early version of the CPAI was initially used in 1990 to assess 100 prison and community-based substance abuse programs within Canada (Gendreau, Goggin, \& Annis, 1990). Since then, the scale has been used to examine both community and prisonbased correctional programs in Canada (Nesovic, 2003), and several US states (Holsinger, 1999; Lowenkamp \& Latessa, 2004; Lowenkamp, Latessa, \& Smith, 2006; Matthews, Hubbard, \& Latessa, 2001). When examining research findings, it has been found that between 20 and $68 \%$ of correctional programs would be rated overall as "unsatisfactory" (Holsinger, 1999; Lowenkamp, Latessa, \& Smith, 2006; Matthews, Hubbard, \& Latessa, 2001; Nesovic, 2003), suggesting that substantial number of treatment programs are not optimal and would fail to yield expected post-program outcomes. Importantly, program integrity is related to performance indicators (e.g., recidivism rates); programs that score lower on the CPAI have poorer offender outcomes (Lowenkamp \& Latessa, 2004; Lowenkamp, Latessa \& Smith, 2006; Nesovic, 2003).

The CPAI has been a key advancement for the field. It allows program administrators to determine the potential strengths and weaknesses of correctional programs being considered for implementation. It also permits a standardized method to evaluate existing programs. The CPAI results provide concrete recommendations towards program improvements, thereby enhancing offender outcomes. There are also broader implications of the CPAI as government agencies are able to determine which aspects of 
correctional programs have the greatest impacts on recidivism (Aos, Phipps, Barnoski, \& Lieb, 2001). Given that budgetary constraints are endemic in the Criminal Justice System, it is important that taxpayer money is used judiciously. The CPAI allows government agencies and policy-makers to fund programs based on fidelity and effectiveness.

\section{Current Study}

The purpose of the current study is to examine aspects of paroling authorities and how they function in order to better define high quality paroling systems. In order to achieve this, the Parole Quality Assurance Inventory (PQAI; Appendix A) has been developed to measure paroling authority quality. The basic underlying assumption is that paroling authorities that possess elements that are empirically known to reduce offending will have lower recidivism rates than those that do not. Efforts will be made to validate this survey by examining its relationship to various parole performance indicators (e.g., rate of failure, rate of sensational failure, percentage of technical failures, gender differences in technical failures, number of appeals per year, number of cases brought to court per year, whether the appeal decisions match the original decisions, grant rate, and percentage of successful parole completions). The areas of paroling authorities that will be considered are (1) Mission/Vision, (2) Organizational Structure, (3) Staff Training, (4) Decision Making Process, (5) Risk Assessment, (6) Violation Process, and (7) Evaluation. As well there is a rating of the auditors' confidence in the scoring of the paroling authority (out of 10).

\section{Research Questions}

(1) Does the PQAI have acceptable psychometric properties? 
(2) Is "paroling authority quality" linked to performance indicators (e.g., rate of failure, rate of sensational failure, percentage of technical failures, gender differences in technical failures, number of appeals, number of cases brought to court, whether appeal decision differs from original decision, grant rate, and percentage of successful parole completions)?

\section{Hypotheses}

Hypothesis 1: The PQAI will demonstrate sufficient psychometric properties (e.g., internal consistency and item-total correlations).

Hypothesis 2: It is expected that performance indicators will fluctuate as a function of the degree of integrity a paroling authority possesses. Paroling authorities who score higher on the PQAI are predicted to have lower rates of failures, lower rates of sensational failures, fewer appeals, fewer cases brought to court, more of those cases brought to court will result in the same decision as the original decision, more successful completions, and less technical violations. ${ }^{6}$

\section{Methods}

\section{Design of the PQAI}

The PQAI is an instrument intended to measure the integrity paroling authorities possess. It examines seven domains: (A) Mission/Vision (13 items), (B) Organizational Structure (23 items), (C) Staff Training (31 items), (D) Decision Making Process (35

\footnotetext{
${ }^{6}$ It is not likely that all of the paroling authorities surveyed will have record of all the performance indicators, however, those where sufficient numbers have been provided will be included in analyses.
} 
items), (E) Risk Assessment (8 items), (F) Violation Process (14 items), and (G)

Evaluation (12 items). Additionally, there is a rating of the auditors' confidence in the accuracy in the scoring of the paroling authority (out of 10).

Development and Iterations of the PQAI. In order to adequately assess the current evidence-based practices of paroling authorities, a measure of parole quality had to be developed. It began with a review of the literature to examine the empirical research regarding best practices in parole. I also expanded my search to include policy-based reports (e.g., reports released by the National Parole Resource Center) in an effort to examine further what industry professionals valued in parole. This process uncovered the seven content areas (e.g., mission/vision, organizational structure, etc.) which appear to be essential for measuring parole quality. Once the content areas were determined, a more detailed review of the literature was conducted in order to determine best practices, with effort being made to include options for all levels of quality paroling authorities may use. My graduate supervisor was invaluable in this capacity as he had a detailed understanding of current parole practices.

Instrumental feedback regarding the content and fidelity of the measure was also provided from external industry professions. This measure was developed with the assistance of an international advisory panel, as well as, discussed and supported by the Standards Committee of the Association of Paroling Authorities International. The members who made up the advisory panel are all industry professionals with expansive knowledge regarding the criminal justice system and evidence-based practices, as well as parole. These individuals included Robbye Braxton (Correctional Program Specialist with the National Institute of Corrections), Nancy Campbell (independent evidence-based 
practices and policy expert), Cathy Banks (retired Project Manager at the National Institute of Corrections), and, lastly, Jean Sutton (retired Director, Professional Standards and Decision Making, Parole Board of Canada). I submitted multiple drafts of the PQAI measure to the advisory panel in order to gain feedback and make improvements. The PQAI underwent several revisions throughout this process in order to include additional items the advisory panel believed were essential when measuring parole quality, as well as, changes in wording to facilitate clarity.

Scoring. The PQAI items are scored so that one point is assigned for each item on the scale. The total number of points in each subscale are then summed and divided by the total number of possible items to provide the subscale score for each section. By aggregating the subscale score, each subsection is weighted equally despite the disparity in length. To calculate a total score, the subscale total scores are aggregated to create a total score. Some items included in the PQAI are descriptive in nature, and therefore, are not included in the scoring procedure.

It is important to remember that as there are differences in the scope and capacity of paroling authorities, as not all paroling authorities have the same responsibilities. Therefore, if a particular item included in the PQAI is not applicable to the paroling authority they have the option mark it as not applicable. This item would then be removed from the subscale score and total score (e.g., the paroling authority could score 9 out of 11 on a subscale as opposed to 9 out of 12 if one item was not applicable to their organization). An example of this would be if the paroling authority is not the decision authority regarding parole violations. Without giving the paroling authority the opportunity to communicate that they do not deal with this area of parole, their PQAI 
scores would be significantly lower than it ought to be or there would be a significant amount of missing data.

\section{Performance Outcome Indicators}

In an effort to validate the PQAI, performance outcome indicators were requested from paroling authorities who participated. This included information such as rate of failure, rate of sensational failure, percentage of technical failures, number of appeals, number of cases brought to court, whether appeal decision differs from original decision, grant rate, and percentage of successful parole completions. Unfortunately, it was difficult to obtain this information as many participants left these sections blank when filling out the questionnaire. A number of paroling authorities indicated that they either did not have access to this data, or the data was not structured in the way we were requesting (e.g., they do not examine failure rates for parolees and offenders who "maxed out" separately). If the paroling authority chose to reveal what state they were from, every attempt was made by the primary researcher to independently obtain this outcome data by retrieving the annual reports of the jurisdiction from the paroling authority website and/or the Department of Corrections.

\section{Study Design}

Through the Association of Paroling Authorities International Standards Committee, paroling authorities were contacted and solicited as to whether they would like to volunteer in the current study, providing a summary of the project and a link to the online survey.

There were significant difficulties in regards to participant recruitment which may have occurred, partially, because of another lengthy survey which was released in close 
proximity to the current study. In an effort to explore different avenues of data collection, the primary researcher attempted to complete questionnaires based on information provided on paroling authority websites; however, due to the lack of information it was determined that this course of action would not be successful.

Furthermore, given the difficulties that arose in recruiting participants, in order to solicit more participation, paper copies of the survey with pre-addressed and pre-stamped envelopes were included in conference packages at the Chairs Meeting of the 2015 Association of Paroling Authorities International Training Conference held in Columbus, Ohio in May 2015. A verbal description of the project, along with the explanation of the benefits to paroling authorities was described during the Chairs Meeting to Parole Chairs who attended.

\section{Results}

\section{Descriptive Statistics}

Thirteen paroling authorities responded to the survey, with nine organizations indicating that they were based in the United States and the remainder choosing not to provide a location. Choice items from the PQAI will now be examined to gain a better understanding of current parole practices.

Mission/Vision. This subscale is intended to examine the overarching goals of the organization and how they are carried out. When asked whether the paroling authority had a vision statement, which was defined as a broad statement that identifies the organization's proposed direction, the majority of paroling authorities indicated that they had a clearly written vision statement $(n=11,91.7 \%)$, one paroling authority did not have one $(7.7 \%)$ and one indicated that this question was not applicable to them $(7.7 \%)$. 
When asked whether the paroling authority had a mission statement, which was defined as a statement that clearly indicates how the organization will operate in light of their vision, just over three quarters of paroling authorities indicated that they did have a mission statement taking into account community safety while recognizing offender rehabilitation can also lead to higher success rates in parole $(n=10,76.9 \%)$. Two paroling authorities indicated that this question was not applicable to their organization $(15.4 \%)$, and one paroling authority indicated that they did not have a mission statement $(7.7 \%)$

It was also of interest as to whether paroling authorities had a strategic plan, which was defined as a systematic process of implementing the mission statement. Just over half of paroling authorities indicated that they somewhat had a strategic plan $(n=7$, $53.8 \%)$. In addition, five paroling authorities had a clearly written plan (38.5\%), and one paroling authority did not have a plan (7.7\%). Of those who did have a strategic plan, one quarter of paroling authorities had a clearly written method to operationalize the goals of the strategic plan $(n=3,25 \%)$, seven paroling authorities had somewhat of a method $(58.3 \%)$ and two paroling authorities did not have a method to operationalize the strategic plan $(16.7 \%)$

Whether paroling authorities have relationships with relevant parole partners was also considered. Findings showed only one paroling authority has regularly meetings with police $(7.7 \%)$, however all paroling authorities meet regularly with corrections partners, and almost all paroling authorities meet with community supervision partners $(92.3 \%)$.

In regards to reaching out to the general public, just over half of paroling authorities do community outreach $(n=7,53.8 \%)$ and just under half of paroling 
authorities do media relations $(n=6,46.2 \%)$. Examining outreach efforts as a whole, $46.2 \%$ of paroling authorities $(n=6)$ do both media relations and community outreach.

Organizational Structure. The second subscale examines how paroling authorities structure their organizations, with relevant areas ranging from hiring practices to budget. Specifically looking at the parole Chair, the average number of years under the present chair was $3.92(S D=2.89)$ and the Chair had an average of 15.25 years of experience $(S D=13.19)$. This experience tended to be quite varied, as can be seen from Table 1, with slightly more parole Chairs having a parole board background. It can be noted that a number of paroling authorities indicated the "other" option. They were able to further specify experience and these areas included state representative, legislation, and community supervision. The selection criteria for hiring new parole Chairs is also quite varied. It is important to note that four paroling authorities $(30.8 \%)$ indicated that this question was not applicable to them, likely indicating that they do not have specific hiring criteria or they are not involved in the hiring process. Of those that do, however, the more frequent criteria were decision-making skills, leadership skills, and criminal justice knowledge. A number of paroling authorities also indicated "other" criteria for parole Chair selection. This included Governor appointment, and unspecified experience in several fields related to parole. 
Table 1

Parole Chair Characteristics

$\mathrm{N} \quad \%$

Past Experience

$\begin{array}{lll}\text { Parole Board } & 8 & 61.5 \\ \text { Corrections } & 7 & 53.8 \\ \text { Court System } & 6 & 46.2 \\ \text { Other } & 4 & 30.8\end{array}$

Criteria for Chair Selection

Decision-making (not restricted

3

23.1

to parole)

Addictions

0

0

Mental Health

0

0

Legal/Policy/Statutes

Leadership

23.1

Human Resources

3

0

Criminal Justice Knowledge $\quad 3$

Political Affiliation

15.4

Other

2

30.8

N/A

4

30.8

Likewise, similar questions were asked regarding parole board members. There were an average of $9.38(S D=4.68)$ board members in the paroling authorities that responded, with the average number of years spent on the board being $4.73(S D=1.49)$. As can be seen from Table 2, the majority of paroling authorities had at least some selection criteria for new board members. The most frequently indicated criteria being knowledge of the criminal justice system and a degree in the human sciences. A number of paroling authorities indicated the "other" option; this included requirements of at least 
one board member with past experience in parole adjacent areas (e.g., at least one board member with past experience in law enforcement, or parole/probation, or victim issues).

Table 2

Board Member Selection

$\mathrm{N} \%$

Criteria for new board

member criteria

No

Somewhat

Yes, written criteria

Yes, explicit written criteria

N/A
1

4

5

2

1

38.5

Degree in human sciences

5

9

69.2

system

Comprehensive decision-

3

23.1

making skills

Extensive communication skills

2

Strong ethical fortitude

2

15.4

Political affiliation

Other

1

4

30.8

N/A

An area of particular interest is whether board member competency is measured at some point during the selection process. The majority of paroling authorities either somewhat $(n=4,30.8 \%)$ or do $(n=6,46.2 \%)$ measure the competency of board members prior to their appointment; while two paroling authorities do not (15.4\%) and 
one indicated that this was not applicable to their organization (7.7\%). Furthermore, just under half of paroling authorities either somewhat $(n=4,30.8 \%)$ or do $(n=2,15.4 \%)$ measure the competency of board members prior to commencing actual decision-making; while six paroling authorities do not $(46.2 \%)$ and one, again, indicates that this question was not applicable to them (7.7\%).

As to whether the demographics of the current board members were comparable to the demographics of the jurisdictions in which they serve, the majority of paroling authorities indicated that they somewhat matched $(n=8,61.5 \%)$; while only three indicated that they did match $(23.1 \%)$, and two paroling authorities indicated that this item was not applicable to their organization (15.4\%).

Considering paroling authorities' budgets, just under half of paroling authorities had independent budgets $(n=6,46.2 \%)$. Of those with dependent budgets, when asked what kinds of factors influenced their budget, paroling authorities indicated the size of prison population $(n=4,30.8 \%$ ), the decision-making capacity (number of board members vs. number of decisions) $(n=4,30.8 \%)$, number of decisions to be made $(n=2$, $15.4 \%)$, and other $(n=2,15.4 \%)$ as being influential factors. Other factors included legislative action $(n=1,7.7 \%)$ and the size of the parole population $(n=1,7.7 \%)$.

The vast majority of paroling authorities produce an annual report, either incorporated into a larger government report $(n=2,15.4 \%)$ or in a standalone document $(n=10,76.9 \%)$; while just one paroling authority does not produce a report $(7.7 \%)$. Furthermore, all organizations that produce a report release it, either in a written report to the Governor or other government organization $(n=3,23.1 \%)$ or on the government website $(n=9,69.2 \%)$. 
Staff Training. As the name suggests, this subscale examines the amount of training and topics covered for both parole Chairs and parole board members. Training provided to both the Chair and board members during their tenure covers a wide range of topics. Popular topics for both parole Chairs and board members, as seen from Table 3, seem to be decision-making, legal/policy/statutes, and risk assessment. However, it appears that there is slightly more focus on those topics for board members than with Chairs. Chairs are trained more often on management skills as reflected in their human resources and leadership training. The amount of time spent on training in the first three months for board members ranges from 40 to 430 hours with an average of 136.18 hours $(S D=120.40)$ 
Table 3

Paroling Authority Training

$\mathrm{N}$

Chair training topics

$\begin{array}{lll}\text { Decision-making (parole specific) } & 8 & 61.5 \\ \text { Legal/policy/statutes } & 7 & 53.8 \\ \text { Leadership } & 5 & 38.5 \\ \text { Human Resources } & 4 & 30.8 \\ \text { Risk Assessment } & 8 & 61.5 \\ \text { Other } & 4 & 30.8 \\ \text { N/A } & 2 & 15.4\end{array}$

Board member training topics

$\begin{array}{lcc}\text { Decision-making (parole specific) } & 11 & 84.6 \\ \text { Legal/policy/statutes } & 11 & 84.6 \\ \text { Leadership } & 3 & 23.1 \\ \text { Human Resources } & 3 & 23.1 \\ \text { Risk Assessment } & 10 & 76.9 \\ \text { Other } & 5 & 38.5 \\ \text { N/A } & 1 & 7.7\end{array}$

Looking in greater detail at the training offered to board members upon being hired, as can be seen from Table 4, the topics offered were quite varied. The most frequently covered topics were risk assessment and decision-making. Whereas, the less frequently covered topics include domestic violence and other specialized needs issues. In contrast, risk assessment and decision-making were still the most frequently covered topics for on-going training; however it appears that training, in general, is less extensive after the initial training period. 
In regards to ongoing training, the majority of paroling authorities offer ongoing training $(n=11,84.6 \%)$ and it comes in the form of conferences $(n=10,76.9 \%)$, workshops ( $n=9,69.2 \%)$, on-the-job training $(n=8,61.5 \%)$, self-development courses $(n=6,46.2 \%)$, other $(n=5,38.5 \%)$, and mentoring $(n=1,7.7 \%)$ 
Table 4

Training Topics

\begin{tabular}{|c|c|c|c|}
\hline & & $\mathrm{N}$ & $\%$ \\
\hline \multicolumn{4}{|l|}{ Initial Training } \\
\hline & Risk assessment & 13 & 100 \\
\hline & Decision-making & 13 & 100 \\
\hline & Victims of crime & 11 & 84.6 \\
\hline & Offender needs & 10 & 76.9 \\
\hline & Offender programming & 10 & 76.9 \\
\hline & Community supervision & 11 & 84.6 \\
\hline & Sex offenders & 10 & 76.9 \\
\hline & Domestic violence & 6 & 46.2 \\
\hline & Specialized needs issues & 6 & 46.2 \\
\hline & Other & 6 & 46.2 \\
\hline \multicolumn{4}{|c|}{ On-going Training } \\
\hline & Risk assessment & 10 & 76.9 \\
\hline & Decision-making & 10 & 76.9 \\
\hline & Victims of crime & 8 & 61.5 \\
\hline & Offender needs & 7 & 53.8 \\
\hline & Offender programming & 7 & 53.8 \\
\hline & Community supervision & 8 & 61.5 \\
\hline & Sex offenders & 9 & 69.2 \\
\hline & Domestic violence & 7 & 53.8 \\
\hline & Specialized needs issues & 7 & 53.8 \\
\hline & Other & 3 & 23.1 \\
\hline & $\mathrm{N} / \mathrm{A}$ & 1 & 7.7 \\
\hline
\end{tabular}

Decision-Making Process. This subscale examines the processes paroling authorities have for the initial release decision. For three-quarters of respondents, the 
parole board member had decision authority for parole decisions $(n=10,76.9 \%)$; while one paroling authority had the parole chair $(n=1,7.7 \%)$, one had the Governor or senior state official $(n=1,7.7 \%)$ and one had another state official $(n=1,7.7 \%)$ being the decision authority.

The majority of paroling authorities did not have a mechanism in place to track the amount of time decision-makers have to examine a case $(n=12,92.3 \%)$; however organizations reported that paroling authorities were provided with a varying amounts of time to review offender cases. Five paroling authorities indicated that board members were given more than 60 minutes to review a case $(38.5 \%)$, two indicated that they were given less than 15 minutes $(15.4 \%)$, two were given $15-30$ minutes $(15.4 \%)$, one was given 30-60 minutes (7.7\%), and three indicated that this question was not applicable in their jurisdiction $(23.1 \%)$. It was reported that paroling authorities expected board members to make, on average, $23.04(S D=17.30)$ parole decisions a day and $59(S D=$ 39.69) parole decisions a week.

The most frequent way in which offenders were included in the initial release decision is through telephone or video appearance $(n=6,46.2 \%)$. Having the offender included via an in-person appearance with no restrictions occurred $30.8 \%(n=4)$ of the time, and in-person appearances with restrictions rarely occurred $(n=1,7.7 \%)$. Lastly, two paroling authorities $(15.4 \%)$ do not include the offender in the decision process and instead rely solely on the offender case file.

All paroling authorities indicated that policy and/or statutes define what specific release criteria paroling authorities take into account when making decisions and all but one paroling authority provide these criteria to the offender. As can be seen from Table 6, 
the most frequent decision criteria used by board members were seriousness of the current offence, the offender's institutional adjustment, history of reoffending on conditional release, victim information, information regarding behaviour in correctional institution/program completion, and release plan and community management strategies. The less frequent decision criteria included marital/family relationships as they relate to risk of reoffending, the age of the offender's first offence and school/work and leisure activities as they relate to risk of reoffending. 
Table 5

Initial Parole Release Decision Factors

\begin{tabular}{|c|c|c|}
\hline & $\mathrm{N}$ & $\%$ \\
\hline Age of first offence & 7 & 53.8 \\
\hline Seriousness of current offence & 13 & 100 \\
\hline Persistence and versatility of criminal behaviour & 9 & 69.2 \\
\hline Criminal behaviour increasing in severity & 8 & 61.5 \\
\hline Institutional adjustment & 13 & 100 \\
\hline $\begin{array}{l}\text { Marital/family relationships as they relate to risk of } \\
\text { reoffending }\end{array}$ & 5 & 38.5 \\
\hline $\begin{array}{l}\text { School/work and leisure activities as they relate to risk of } \\
\text { reoffending }\end{array}$ & 7 & 53.8 \\
\hline $\begin{array}{l}\text { System/background factors which may have contributed to } \\
\text { criminal behaviour }\end{array}$ & 11 & 84.6 \\
\hline History of reoffending on conditional release & 12 & 92.3 \\
\hline History of breaching conditions on conditional release & 10 & 76.9 \\
\hline History of escape/escape attempts & 8 & 61.5 \\
\hline Victim information & 13 & 100 \\
\hline Actuarial measures of the risk to reoffend & 11 & 84.6 \\
\hline $\begin{array}{l}\text { Information regarding behaviour in correctional } \\
\text { institution/program completion }\end{array}$ & 13 & 100 \\
\hline Release plan and community management strategies & 13 & 100 \\
\hline
\end{tabular}

It is important to note, however, that less than half of paroling authorities $(n=6$, $46.2 \%$ ) utilized structured guidelines regarding these factors to assist board members in their decision-making. This may be an indication that paroling authorities are not considering factors in a consistent manner. However, paroling authorities do have policy and statutes that provide guidelines for paroling authorities in other areas. They inform 
them on the eligibility of the offender for release $(n=11,92.3 \%)$, the specific decision factors they should be taking into account $(n=11,84.6)$, the type of mandatory release conditions to place on the offender $(n=8,61.5 \%)$, the type of special release conditions to place on the offender $(n=5,38.5 \%)$, the weight they should be placing on decision factors $(n=3,23.1 \%)$, and the number of release conditions to place on the offender $(n=$ 2, 15.4\%). Additionally, all paroling authorities have a website that informs the general public about parole.

An area getting increased attention is the role victims play in the parole decision process (Morgan \& Smith, 2005). As seen in Table 5, all paroling authorities take into account victim information. Furthermore, all paroling authorities permit victim involvement through either a written or oral statement. However, only one paroling authority $(7.7 \%)$ provides board members with specific guidelines on what weight they should place on these victim impact statements.

Proceeding to community supervision decisions, just over half of paroling authorities allow for the shortening in length of the parole supervision period as an incentive for good parole behaviour $(n=7,53.8 \%)$.

When examining the number of mandatory parole conditions placed on offenders by parole boards, the amount ranged from 0 to 12 conditions with an average of 7.36 (SD $=4.18$ ). When looking at the number of mandatory and special parole conditions combined, the average number placed on offenders ranged from 7 to 25 with an average of $12.9(S D=5.02)$. Twelve paroling authorities indicated that they use parole conditions to hold offenders accountable. When prompted how, all paroling authorities indicated they were used to ensure offender compliance $(n=12,100 \%)$, half indicated they were 
used to ensure offender motivation ( $n=7,53.8 \%$ ), and one third of paroling authorities reduce conditions over time with supervision success $(n=4,30.8 \%)$. Furthermore, all paroling authorities indicated that parole conditions were used to manage offender risk. When prompted how, these were the given reasons: parole conditions are linked to criminogenic needs $(n=9,69.2 \%)$, higher risk offenders receive more parole conditions ( $n=6,46.2 \%)$, lower risk offenders receive fewer parole conditions ( $n=5,38.5 \%)$, frontloading of conditions $(n=5,38.5 \%)$, and parole conditions are linked to the offenders' release plan $(n=4,30.8 \%)$.

Lastly, many paroling authorities were required to provide a written rationale for their decision, either a summary $(n=7,53.8 \%)$ or a detailed decision rationale $(n=1$, 7.7\%). However five paroling authorities indicated that they were not required to provide the offender with a written rationale $(38.5 \%)$.

Risk Assessment. This subscale is about the risk assessment instruments utilized by paroling authorities. The majority of paroling authorities use actuarial assessments of risk, with ten paroling authorities using scales that use static and dynamic factors (76.9\%) and two using static, dynamic, and protective factors (15.4\%). Conversely, one paroling authority uses structured professional judgement to measure offender risk of recidivism (7.7\%). Regarding the value board members place on these assessments, all paroling authorities rate the risk assessment score as being important $(n=6,46.2 \%)$ or very important $(n=7,53.8 \%)$.

Encouragingly, almost all paroling authorities indicated that their risk assessment instrument had been validated on their offender population $(n=11,84.6 \%)$, while one 
organization did not use a risk instrument that had been validated on their offender population (7.7\%) and one was unsure about instrument validation (7.7\%).

Lastly, as can been seen from Table 6, very few paroling authorities utilize specialized risk assessment instruments for particular subgroups of offenders, with the exception of sex offenders.

Table 6

Specialized Risk Assessment Instruments

\begin{tabular}{lcc}
\hline & $\mathrm{N}$ & $\%$ \\
\hline Ethnic subgroups/Indigenous & 0 & 0 \\
offenders & 11 & \\
Sex offenders & 1 & 84.6 \\
Mentally disordered offenders & 0 & 7.7 \\
Domestic violence offenders & 2 & 0 \\
Substance abuse offenders & 2 & 15.4 \\
N/A & & 15.4 \\
\hline
\end{tabular}

Violation Decision Process. Beyond the initial release decisions, paroling authorities often make decisions regarding parole violations. Most paroling authorities indicated that the parole board member had decision authority for parole violation decisions ( $n=9,69.2 \%)$; while two indicated it to be the parole supervisor $(15.4 \%)$, one indicated it to be the parole chair $(7.7 \%)$ and one indicated that this question was not applicable to their organization $(7.7 \%)$.

Offenders are largely included in the parole violation decision process through an in-person appearance that includes all criteria $(n=6,46.2 \%)$; while three paroling authorities include the offender through telephone/video appearance (23.1\%), and one 
organization utilizes in-person appearances with select offence criteria (7.7\%). This is in contrast with three paroling authorities who do not include the offender in the process and who, instead, solely rely on offender case files (23.1\%),

The majority of paroling authorities have policy and/or statutes which define what specific criteria board members should be taking into account when making parole violation decisions, either specific to violations $(n=7,53.8 \%)$ or specific to the type of crime $(n=1,7.7 \%)$. Only three paroling authorities $(23.1 \%)$ had policy and/or statutes define how to assess these criteria. Of those who do have guidelines, two thirds provide these to the offender $(n=6,46.2 \%)$.

Table 7 outlines what these criteria are. The most frequent decision criteria were the circumstances surrounding the parole violation, and documented drug use. The least frequent criteria considered are actuarial measures of risk and the release plan and community management strategies for continuing the release. 
Table 7

Violation Decision Factors

\begin{tabular}{|c|c|c|}
\hline & $\mathrm{N}$ & $\%$ \\
\hline Actuarial measures of the risk to reoffend & 2 & 15.4 \\
\hline Seriousness of current violation & 6 & 46.2 \\
\hline Past criminal behaviour trends & 4 & 30.8 \\
\hline $\begin{array}{l}\text { The offender's correctional or offender } \\
\text { accountability plan progress while in the }\end{array}$ & 4 & 30.8 \\
\hline community and identified needs and risk factors & & \\
\hline $\begin{array}{l}\text { Any documented episodes of drug use or positive } \\
\text { urinalysis tests }\end{array}$ & 7 & 53.8 \\
\hline $\begin{array}{l}\text { The circumstances surrounding the parole } \\
\text { violation }\end{array}$ & 8 & 61.5 \\
\hline $\begin{array}{l}\text { The release plan and community management } \\
\text { strategies for continuing the release }\end{array}$ & 3 & 23.1 \\
\hline Parole officer recommendation & 6 & 46.2 \\
\hline $\mathrm{N} / \mathrm{A}$ & 1 & 7.7 \\
\hline
\end{tabular}

Lastly, approximately two thirds of paroling authorities are required to provide the offender with a written rationale for their violation decision $(n=8,61.5)$.

Evaluation. This subscale is concerned with how paroling authorities evaluate their performance. All paroling authorities indicated that they have a parole decisions database. Just under half of the paroling authorities maintain this database themselves ( $n$ $=6,46.2 \%)$, while six indicated that the Department of Corrections maintains it $(46.2 \%)$ and one paroling authority indicated that another government department maintains this database (7.7\%). Just under half of these databases include the decisions, condition imposed on the offender, and the reasons for the decision $(n=6,46.2 \%)$, five only 
include the decisions (38.5\%) and two include decisions and condition imposed on the offender (i.e., no reasons for decisions; 15.4\%).

The majority of paroling authorities keep data regarding recidivism outcomes of the offenders they make decisions on $(n=11,84.6 \%)$. Regarding access to this data, nine paroling authorities have access to aggregated recidivism outcomes (69.2\%) and seven have access to data regarding recidivism outcomes for individual cases (53.8\%). It is usually the Department of Corrections who maintains this database $(n=7,53.8 \%)$, or the paroling authority $(n=3,23.1 \%)$, or, finally, another government department $(n=3$, $23.1 \%)$

As can be seen from Table 8 , the recidivism database tends to include a wide variety of pertinent data. With paroling authorities more frequently keeping track of data regarding new crimes and parole revocations due to parole violations. Comparatively, they are less likely to record new violent crimes and violations of parole conditions (without revocation).

Table 8

Contents of Recidivism Database

\begin{tabular}{lcc}
\hline & $\mathrm{N}$ & $\%$ \\
\hline Violations of parole conditions & 9 & 69.2 \\
Revocation due to parole violations & 12 & 92.3 \\
New crimes & 13 & 100 \\
New violent crimes & 7 & 53.8 \\
Absconders & 10 & 76.9 \\
Technical violations & 11 & 84.6 \\
\hline
\end{tabular}


Just over half of paroling authorities include performance indicators in the annual report $(n=7,53.8 \%)$.

Lastly, the majority of paroling authorities allow public access to information about decisions, either by written request $(n=4,30.8 \%)$, website $(n=6,46.2 \%)$, or verbal request $(n=1,7.7 \%)$.

Subsection H: Confidence. On a scale of one to ten (with ten being very confident) paroling authorities rated their confidence that their evaluation of the organization was completed with correct information as, on average, $7.31(S D=1.11)$ with a range of five to nine.

\section{Psychometric Properties}

Hypothesis 1 stated that the PQAI would demonstrate sufficient psychometric properties, which was examined by the internal consistency of the scale: (a) item-total score correlations of .30 or greater, average inter-item correlations ranging from .2 to .4, and (b) Cronbach's alpha of .70 or greater (Nunnally, 1978). As participants were able to select out of questions that were not applicable to their organization, the decision was made to dichotomize each item for only the psychometric analyses, so that internal consistency analyses would run. When asked whether the paroling authority had a vision statement, for example, any response other than "yes" would have resulted in a value of zero (e.g., the other options were they didn't have a vision statements or this questions was not applicable to their organization). The variance of responses for the majority of items allowed for this; however, it did reduce the variability of some items and the findings should be accepted with caution. 
Hypothesis testing began with the original 95 questions, and it was found that over half of the items were found to have insufficient internal consistency; reducing the number of items included in the PQAI to be 40. See Appendix B for a complete itemization of the reduced PQAI. Next, each subscale was examined individually.

Subscale A: Mission/Vision. The mission and vision subscale of the PQAI examines the overarching goals for the organization and initially contained 13 items. This subscale originally had a Cronbach's alpha of .580 which was insufficient. When an item had a low item-total correlation $(<.30)$ or would increase the Cronbach's alpha if deleted, it was eliminated from the PQAI. This procedure resulted in the removal of six items. The subscale had a final Cronbach's alpha of .726 and an average inter-item correlation of .275 . Table 9 provides a summary of the item-total correlations for the seven items retained in the subscale. 
Table 9

Item Statements of the Mission/Vision Subscale of the PQAI

\begin{tabular}{lcc}
\hline Item Statement & $\begin{array}{c}\text { Item-total } \\
\text { correlation }\end{array}$ & $\begin{array}{c}\text { Cronbach's Alpha } \\
\text { if Item deleted }\end{array}$ \\
\hline $\begin{array}{l}\text { 1. Does the paroling authority have a vision } \\
\text { statement? }\end{array}$ & .407 & .702 \\
4. Does the paroling authority do community & .464 & .687 \\
outreach? & & .726 \\
5. Does the paroling authority do media & .316 & .612 \\
relations? & & .695 \\
8. Does the paroling authority have a & .732 & .715 \\
strategic plan? & .431 & .704 \\
9. Is there a plan or method to operationalize \\
the goals of the strategic plan? \\
$\begin{array}{l}\text { 10. If yes, how often is the strategic plan or } \\
\text { method reviewed? }\end{array}$ \\
$\begin{array}{l}\text { 11. If yes, is the strategic plan available } \\
\text { online? }\end{array}$
\end{tabular}

Subscale B: Organizational Structure. The organizational structure subscale examines the underlying configuration of the paroling authority including their hiring processes and initially contained 13 items. This subscale originally had a Cronbach's alpha of .728, however numerous items had insufficient item-total correlations. Using the same item removal procedures as in subscale A (Mission/Vision), seven items were deleted. The average inter-item correlation was .333 and the final Cronbach's alpha was .873. Table 10 provides a summary of the item-total correlations for the six items retained in the instrument. 
Table 10

Item Statements of the Organizational Structure Subscale of the PQAI

\begin{tabular}{lll}
\hline Item Statement & Item-total & Cronbach's Alpha \\
& correlation & if item deleted
\end{tabular}

4. Are there criteria for new parole chair selection?

Decision-making (not restricted to parole)

Legal/Policy/Statutes

Leadership .765 .470

Criminal Justice Knowledge

Political Affiliation

.577

.678 8a. Are there criteria for new board member selection?

Knowledge of the criminal justice system

and the associated issues

9. Is board member competency considered

prior to their appointment, through interview

or other standardized assessment method?

10. Following initial training, is board

.614
.866

member competency measured, through interview or other standardized assessment method prior to their making decisions?

15. If there is a process for board members' terms to be renewed, which factors are considered?

Political affiliation

Demonstrated competence .642

Criminal justice knowledge .633 .860

Unique Perspective (e.g., victim rights 
advocate, etc.)

18. Do any of the following factors influence budget allocation

Number of decisions

Size of prison population

Subscale C: Staff Training. The third subscale of the PQAI examines the training topics and amount of training provided to the paroling authority. This subscale originally had eight items with a Cronbach's alpha of .909 , however a number of items had insufficient item-total correlations to be maintained. This subscale was reduced to five items which had a Cronbach's alpha of .951 and an average inter-item correlation of .443. Table 11 provides a summary of the item-total correlations for the five items retained in the instrument. 
Table 11

Item Statements of the Staff Training Subscale of the PQAI

\begin{tabular}{lll}
\hline Item Statement & Item-total & Cronbach's Alpha \\
& Correlation & if item deleted
\end{tabular}

1. Are training/mentoring protocols provided

to the Chair during their tenure?

Decision-making (parole specific)

.675

.948

Legal/Policy/Statutes

.747

.947

Leadership

.465

.951

Human Resources

.696

.948

Risk Assessment

.675

.948

2. Are training/mentoring protocols provided

for Board Members during their tenure?

Decision-making (parole specific)

.490

.950

Legal/Policy/Statutes

.490

.950

Leadership

.545

.950

Human Resources

.628

.949

Risk Assessment

.673

.948

5. What topics are covered in initial training?

Domestic Violence

.573

.950

Other specialized needs issues

.455

.951

7. Do board members get ongoing/yearly

.396

.951

training days?

7d. If yes, what training topics are covered?

Risk Assessment

Decision-making

Victims of crime

.800

Offender needs

.919

.945

Offender programming

.919

.945

Community supervision

.800

.947 
Sex offenders

Domestic Violence

Specialized needs issues
.752

.947

.674

.948

.919

Subscale D: Decision-Making Process. The fourth subscale of the PQAI examines the paroling authorities' process for making release decisions. This subscale originally had 31 items with a Cronbach's alpha of .706, however numerous items had insufficient item-total correlations to be maintained. This subscale was reduced to 10 items which had a Cronbach's alpha of .889 and an average inter-item correlation of .297. Table 12 provides a summary of the item-total correlations for the ten items retained in the instrument. 
Table 12

Item Statements of the Decision-Making Process Subscale of the PQAI

\begin{tabular}{lll}
\hline Item Statement & Item-total & Cronbach's Alpha \\
correlation & if item deleted
\end{tabular}

2. Can the decision authority veto Board .408 .888 Member decisions?

11. Can offenders have legal representation .365 .888 during the parole decision process? 12b. If policy and/or statutes define what specific release criteria paroling authorities should be taking into account, check all that apply.

Persistence and versatility of criminal .880 .870 behaviour

Criminal behaviour increasing in severity .675 .878

Systemic/background factors which may

have contributed to criminal behaviour

History of reoffending on conditional

release

History of breaching conditions on

conditional release

13. Are there structured decision guidelines

regarding these factors to assist board members in parole decisions?

14. When making a parole decision, what

importance does your agency place on the type of crime?

15. Is there importance placed on the type of crime reflected in policy and/or statutes?

17. Which policy and/or statutes inform 
paroling authorities?

Eligibility (timing) $\quad .470$

.886

Type of release conditions (special)

Decision factors (the weight they should

place on these factors)

21. Are board members given specific

guidelines on what weight they should place

on victim impact statements?

31. If parole conditions are used to manage offender risk, how?

Lower risk offenders receive fewer parole

conditions

Higher risk offenders receive more parole conditions

Parole conditions are linked to the

offenders' release plan

Frontloading of conditions place for offenders to utilize?

Subscale E: Risk Assessment. The fifth subscale of the PQAI examines the risk assessment instruments utilized by the paroling authority. This subscale originally had 6 items with a Cronbach's alpha of .376 . This subscale was reduced to two items which had a Cronbach's alpha of .700 and an average inter-item correlation of .492. Table 13 provides a summary of the item-total correlations for the two items retained in the instrument. 
Table 13

Item Statements of the Risk Assessment Subscale of the PQAI

\begin{tabular}{lcc}
\hline Item Statement & $\begin{array}{c}\text { Item-total } \\
\text { correlation }\end{array}$ & $\begin{array}{c}\text { Cronbach's Alpha } \\
\text { if item deleted }\end{array}$ \\
\hline 5. Are there specialized risk instruments for & & \\
particular types of offenders? & .746 & .424 \\
Mentally disordered offenders & .487 & .645 \\
Substance abuse offenders & .415 & .786 \\
7. Do the risk measures provide a probability & & \\
estimate of likelihood of failure? & & \\
\hline
\end{tabular}

Subscale F: Violation Decision Process. The penultimate subscale of the PQAI examines the decision-making process for parole violation decisions. This subscale originally had 12 items with a Cronbach's alpha of .841 ; however there were a number of item-total correlations which were below the .30 cut-off. This subscale was reduced to five items which had a Cronbach's alpha of .928 and an average inter-item correlation of .509. Table 14 provides a summary of the item-total correlations for the five items retained in the instrument. 
Table 14

Item Statements of the Violation Decision Process Subscale of the PQAI

\begin{tabular}{|c|c|c|}
\hline Item Statement & $\begin{array}{l}\text { Item-total } \\
\text { correlation }\end{array}$ & $\begin{array}{l}\text { Cronbach's Alpha } \\
\text { if item deleted }\end{array}$ \\
\hline $\begin{array}{l}\text { 7. Do policy and/or statutes define what } \\
\text { specific criteria paroling authorities should be } \\
\text { taking into account when dealing with parole } \\
\text { violations? }\end{array}$ & .914 & .913 \\
\hline $\begin{array}{l}\text { 7a. If yes, are these provided to the offender? } \\
7 \mathrm{~b} \text {. If yes, do they include: }\end{array}$ & .579 & .927 \\
\hline Actuarial measures of the risk to reoffend & .435 & .931 \\
\hline Seriousness of current violation & .840 & .916 \\
\hline Past criminal behaviour trends & .646 & .924 \\
\hline $\begin{array}{l}\text { The offender's correctional or offender } \\
\text { accountability plan progress while in the } \\
\text { community and identified need and risk } \\
\text { factors }\end{array}$ & .692 & .922 \\
\hline $\begin{array}{l}\text { Any documented episodes of drug use or } \\
\text { positive urinalysis tests }\end{array}$ & .885 & .914 \\
\hline $\begin{array}{l}\text { The circumstances surrounding the parole } \\
\text { violation }\end{array}$ & .914 & .913 \\
\hline $\begin{array}{l}\text { The release plan and community } \\
\text { management strategies for continuing } \\
\text { release }\end{array}$ & .485 & .929 \\
\hline Parole officer recommendation & .664 & .923 \\
\hline $\begin{array}{l}\text { 8. Are there structured decision guidelines } \\
\text { regarding these factors to assist board } \\
\text { members in parole violation decisions? }\end{array}$ & .472 & .931 \\
\hline $\begin{array}{l}\text { 9. Do policy and/or statutes provide } \\
\text { structured decision guidelines for paroling }\end{array}$ & .751 & .920 \\
\hline
\end{tabular}


authorities in parole violation decisions?

Subscale G: Evaluation. The final subscale of the PQAI examines how paroling authorities evaluate their performance. This subscale originally had 12 items with a Cronbach's alpha of .608 with many item-total correlations below the .30 cut-off. This subscale was reduced to five items resulting in a Cronbach's alpha of .757 and an average inter-item correlation of .305 . Table 15 provides a summary of the item-total correlations for the five items retained in the instrument.

Table 15

Item Statements of the Evaluation Subscale of the PQAI

\begin{tabular}{lll}
\hline Item Statement & Item-total & Cronbach's Alpha \\
& correlation & if item deleted
\end{tabular}

2. Who maintains the parole decisions

.358

.752 database?

5. Do you have access to data regarding .363 aggregated recidivism outcomes?

6. Do you have access to data regarding recidivism outcomes for individual cases?

7. Who maintains the recidivism database?

8. What is included in the recidivism database?

Violations of parole conditions

Revocation due to parole violations

Absconders 
Total PQAI. Once unreliable items were removed from each of the subscales $(n=$ $55)$, the psychometric properties of all remaining items were examined $(n=40)$. As a whole, the PQAI has a Cronbach's alpha of .935. There were item-total and inter-item correlations which violated the pre-defined cut-offs; however, if these items were removed there would have been a significant reduction of items. It was decided that the items in question would remain in the measure. $^{7}$

PQAI Version Comparison. Once the psychometric properties of the PQAI were examined, two versions of this quality measure were then scored. The original version includes all 95 items; whereas, the reduced version of the PQAI includes only the 40 items that which had sufficient reliability when individually evaluating each subscale.

As can be seen from Table 16, when all possible items were included, paroling authorities consistently endorsed more of these items with less variability in scores for all subscale and total scores, with average scores ranging from .61 to .72. However, when the reduced version of the PQAI was scored, paroling authorities endorsed fewer of the items with greater variability in subscale and total scores. This difference is particularly evident in the risk assessment subscale where the average subscale score when scoring the original PQAI resulted in .72; however in the reduced version the average score was .17. This difference coincides with this subscale having a significant reduction in items from poor psychometric properties, going from including seven items to just two.

\footnotetext{
${ }^{7}$ Correlation analysis was completed with and without these items included in the PQAI and results did not significantly differ.
} 
Table 16

Distribution of the Original PQAI in comparison to the Reduced PQAI

\begin{tabular}{|c|c|c|c|}
\hline & Minimum & Maximum & $\mathrm{M}(\mathrm{SD})$ \\
\hline \multicolumn{4}{|l|}{ Original Version } \\
\hline Mission/Vision & .33 & .92 & $.67(.16)$ \\
\hline Organizational & .34 & .84 & $.61(.16)$ \\
\hline \multicolumn{4}{|l|}{ Structure } \\
\hline Staff Training & .50 & .97 & $.73(.14)$ \\
\hline Decision-Making & .57 & .77 & $.64(.07)$ \\
\hline \multicolumn{4}{|l|}{ Process } \\
\hline Risk Assessment & .50 & .83 & $.72(.09)$ \\
\hline Violation & .45 & .96 & $.70(.17)$ \\
\hline \multicolumn{4}{|l|}{ Decision Process } \\
\hline Evaluation & .30 & .89 & $.62(.18)$ \\
\hline Total PQAI & .55 & .82 & $.67(.09)$ \\
\hline \multicolumn{4}{|l|}{ Reduced Version } \\
\hline Mission/Vision & 0 & 1 & $.62(.28)$ \\
\hline Organizational & .20 & .85 & $.46(.23)$ \\
\hline \multicolumn{4}{|l|}{ Structure } \\
\hline Staff Training & .20 & 1 & $.65(.25)$ \\
\hline Decision-Making & .17 & .82 & $.53(.19)$ \\
\hline \multicolumn{4}{|l|}{ Process } \\
\hline Risk Assessment & 0 & 1 & $.17(.31)$ \\
\hline Violation & 0 & .98 & $.50(.40)$ \\
\hline \multicolumn{4}{|l|}{ Decision Process } \\
\hline Evaluation & 0 & 1 & $.57(.32)$ \\
\hline Total PQAI & .22 & .81 & $.50(.16)$ \\
\hline
\end{tabular}


Factor Structure. In order to assess the appropriateness of the structure of the PQAI for use in paroling authority samples, exploratory factor analysis was proposed. However, given the small sample size, this analysis was unable to compute; therefore, it was decided to abandon this analysis technique for the time being.

\section{Correlation Analysis}

Hypothesis 2 expected that performance indicators would fluctuate as a function of the degree of integrity a paroling authority possesses. As there was difficulty obtaining performance indicators, correlation analyses were only completed when at least half of the respondents had a value on the outcome variable. As such, only the correlation between PQAI subscale and total scores with the percentage of offenders who had a community failure were examined $(n=9)$. Correlation analysis was done utilizing both the original scale, as well as, the reduced version.

Initially, Pearson's correlation was the proposed analytic technique; however, upon closer inspect of the data it was found that a number of the predictor variables (Organizational Structure, Risk Assessment, Violation Decision Process, and Evaluation) and the outcome variable were not normally distributed. Unfortunately, normality is a parametric assumption for significance testing on bivariate correlations (Field, 2009). Alternatively, Spearman's correlation coefficient was utilized, as there are not the same assumption requirements.

As can be seen from Table 17, there were no significant relationships between the original PQAI and the percentage of offenders who reoffended while on parole. These results should be accepted with caution as there was a very small sample size, which may yield unreliable findings. 
Table 17

Bivariate Correlations among Original PQAI \& Percentage of Offenders who Reoffended

\begin{tabular}{lccc}
\hline PQAI & $\mathrm{r}$ & $\mathrm{p}$ & $95 \% \mathrm{CI}$ \\
\hline Vision/Mission & -.134 & .365 & {$[-.73, .58]$} \\
Organizational & .050 & .449 & {$[-.64, .69]$} \\
Structure & & & \\
Staff Training & -.092 & .407 & {$[-.71, .61]$} \\
Decision-Making & -.234 & .272 & {$[-.78, .51]$} \\
Process & & & \\
Risk Assessment & .050 & .449 & {$[-.64, .69]$} \\
Violation Decision & .183 & .318 & {$[-.55, .76]$} \\
Process & & & \\
Evaluation & -.286 & .228 & {$[-.80, .47]$} \\
PQAI Total Score & -.050 & .449 & {$[-.64, .69]$} \\
\hline
\end{tabular}

Note. $\mathrm{CI}=$ confidence interval

Furthermore, Table 18 reveals there were no significant relationships between the reduced PQAI and the percentage of offenders who reoffended while on parole. These results should be accepted with caution; however, as the sample size was very low which may produce unreliable results. 
Table 18

Bivariate Correlations among Reduced PQAI \& Percentage of Offenders who Reoffended

\begin{tabular}{lccc}
\hline PQAI & $\mathrm{r}$ & $\mathrm{p}$ & $95 \% \mathrm{CL}$ \\
\hline Vision/Mission & -.067 & .432 & {$[-0.70,0.62]$} \\
Organizational & -.500 & .085 & {$[-0.87,0.25]$} \\
Structure & & & \\
Staff Training & -.067 & .432 & {$[-0.70,0.62]$} \\
Decision-Making & .067 & .432 & {$[-0.62,0.70]$} \\
Process & & & \\
Risk Assessment & .000 & .500 & {$[-0.66,0.66]$} \\
Violation Decision & .220 & .284 & {$[-0.52,0.77]$} \\
Process & & & \\
Evaluation & -.360 & .171 & {$[-0.83,0.40]$} \\
PQAI Total Score & -.167 & .334 & {$[-0.75,0.56]$} \\
\hline
\end{tabular}

Note. $\mathrm{CI}=$ confidence interval

Additional analyses done with $\mathrm{G}^{*}$ Power 3.1.9.2 indicates that these are underpowered correlations and that a total sample size of 84 participants would be needed to analyze the data with sufficient power. Unfortunately, this amount of participants likely exceeds the number of paroling authorities available to participate.

\section{Discussion}

\section{Summary of Findings}

Based on the results of the current research, the PQAI was unable to be validated. Although, with large amount of removed items, the scale was able to, for the most part, achieve sufficient psychometric properties. More specifically, there was no significant association between PQAI subscale and total scores with the proportion of offenders who 
failed in the community. However, just because it did not appear that performance outcomes did not fluctuate as a function of parole quality, this does not necessarily mean the relationship does not exist. These results can likely be attributed to under-powered analyses with a small sample size. Furthermore, the reduction of items included in the quality measure may have impacted the association with performance outcome, as there is the need to balance the need for a reliable measure with the need for it to include face valid items. Nevertheless, just because the PQAI was unable to be validated, does not mean nothing of value has come from this project. PQAI responses have revealed rich details of paroling authorities and how they function. By conducting this research, we are better placed to understand where paroling authorities are in relation to best practices; allowing us to comment on particular strengths and training needs of these organizations.

\section{Implications of Findings}

Transparency. Public confidence in the criminal justice is low; particularly in parole (Latimer \& Desjardins, 2007) and much of this criticism stems from the lack of transparency of paroling organizations (Schwartzapfel, 2015). Paroling authorities are considered a black box, with offenders and the general public unclear regarding how board members make decisions. Consequently, this lack of transparency can have a substantial effect on how offenders view the criminal justice system. Research has shown that when there are inconsistencies in what offenders believe are the decision factors used in their case and what factors board members actually use when making a decision, offenders will increasingly feel confusion and frustration. These negative feelings could then fuel fear and resentment throughout the prison population (West-Smith, Pogrebin \& Poole, 2000). 
There are many ways in which paroling authorities can make their organizations more transparent in a bid to gain greater support. First, they can have policies and statutes that mandate what factors are taken into account when making decisions; then making more clear and consistent decisions. It is also important that these be accessible to interested parties (e.g., the offender, victims, general public). Encouragingly, of the paroling authorities who participated in this project, all have policies that determine what decision criteria are and almost all of these organizations provide offenders with this information.

An additional way in which paroling authorities can make their organizations more transparent is by providing offenders with detailed decision rationales as an explanation of why they may have been denied parole, as well as, a resource for the offender to improve their case for future parole hearings. A common criticism of parole by offenders is that they are often provided no explanation of why they were denied release, or simply a vague summary (Schwartzapfel, 2015). Unfortunately, based on the current findings, these criticisms may be well placed, as it does not appear that paroling authorities are providing offenders with detailed explanations for their decisions. Paroling authorities should consider increasing the amount of explanation they provide to offenders when making decisions in an effort to increase organizational transparency, and thus, gain more legitimacy in the eyes of the offender.

Lastly, there are a number of actions that paroling authorities can undertake in order to educate the public about the realities of parole. This is an area in need of improvement as approximately half of paroling authorities do not do any sort of community outreach or media relations. Media relations may be particularly helpful when 
there is a sensational failure in the community and the paroling authority wants to educate the public on the complex reasons offenders may reoffend which may be outside of the parole boards' control (e.g., changes in dynamic risk). By having more open lines of communication with the public, the paroling authority may be able to reduce some of the criticism they often deal with and improve the public's perceptions of the parole system.

Selection Practices. Paroling authorities have been widely criticized in the past for having highly political selection practices (Schwartzapfel, 2015). Paparozzi and Caplan (2009) found that the majority of parole appointments are made by the state Governor, with only four states advertising board openings. When examining board member requirements, the majority of the U.S. states had unclear or non-existent education and work requirements.

Based on the current findings, it was found that only one paroling authority had explicit and written selection criteria when considered individuals for a board member position. Also, a number of paroling authorities indicated that selection was largely up to the Governor's discretion. It would be beneficial if paroling authorities adopted a more transparent and skills/knowledge-based selection process, as they may be more likely to attract qualified candidates for the position and enhance public confidence (Campbell, 2008).

Encouragingly, a large proportion of the paroling authorities indicated that they measure board member competency through an interview or other standardized assessment method during the selection process. This is important as it suggests that board members may be selected based on their knowledge and skills. While it was outside of the scope of the current project, it is of interest how competency is being 
assessed and what board member characteristics are being valued and sought in potential candidates. The current research did not examine this, but this is an area for future study.

Staff Training. It appears as though parole board members undergo extensive training in a variety of areas; however, the training parole Chairs receive may be of concern. Based on the current findings, parole Chairs appear to receive more management-related training (e.g., training in leadership and human resource areas), as opposed to decision-related training (e.g., training in decision-making and risk assessment areas), when compared to board members. The roles and responsibilities of the parole Chair can vary based on the jurisdiction in which they serve (Campbell, 2008); however, they are often included in the decision-making process, making decisions alongside board members. Given that parole Chairs make release decisions, it is just as essential that they be well trained in relevant areas as for board members. Paroling authorities should examine their organizations to ensure that sufficient training is provided to all necessary individuals based on the roles they are responsible for.

Risk Assessment. All paroling authorities who took part in this research used either structured professional judgement or an actuarial assessment of risk of recidivism as part of decision-making. This is encouraging as research has shown these methods to be superior over unstructured clinical judgement (Bengtson \& Långström, 2007; Meehl, 1996). It is also encouraging that paroling authorities are using risk instruments that have been validated on their own offender population as research has shown that risk instruments do not always predict recidivism with the same degree of accuracy on offender populations where it has not been validated (Serin \& Lowenkamp, in press; Wright, Clear, \& Dickson, 1984). 
An area for improvement, however, would be the adoption of risk instruments for particular subgroups of offenders. With the exception of sex offenders, paroling authorities rarely utilized special risk assessment instruments. This is problematic as other offenders (e.g., domestic violence offenders or women offenders) have special risk factors or criminogenic needs that should be more accurately accounted for with risk assessment instrument that accounts for these (Bumby, Carter, Talbot, \& Gilligan, 2007; Hanson, 2009; Hardyman \& Van Voorhis, 2004; Heilbrun, Goldstein, \& Redding, 2005; Ho, Thomson, \& Darjee, 2009; Serin \& Lowenkamp, in press). Domestic violence offenders, for example, are a subgroup of offenders for which unique risk factors are present (e.g., breach on non-contact orders) and reflected in specialist risk scales. An example would be the Ontario Domestic Assault Risk Assessment which has been found to predict domestic violence recidivism with greater accuracy than a general risk assessment (Hilton, Harris, Popham, \& Lang, 2010). Without the use of specialist risk instruments, paroling authorities may be attenuating the accuracy of their assessments, increasing the false negative and false positive rates; allowing dangerous offenders into the community and keeping appropriate offenders incarcerated.

Structured Decision-Making Practices. For the majority of paroling authorities, policy and statutes require board members to take into account specific decision factors; however, the majority of paroling authorities do not have structured decision guidelines to help them in determining the weight which should be placed on these factors (e.g., how they should be considering victim impact statements). This is problematic as research has found that decision-makers, while taking into consideration similar factors, can differ in the way they weight them (Samra, 1997). More specifically, decision-makers who favour 
parole, weigh rehabilitative criteria (e.g., participating/benefiting from correctional programming, proposed release plan) more heavily than those opposing parole (Samra, 1997). If board members are considering decision factors differently, the risk of making inconsistent decisions increases.

An alternative to unstructured consideration of policy-determined decision criteria would be to use structured decision guidelines to aid board members in how they consider decision factors. An established example of this would be the Structured Release Decision Framework (Serin, 2004) which has been implemented in Canada's federal parole system and modified for use in some U.S. jurisdictions. This empirically-based tool, which begins with a consideration of the statistical risk estimate, provides board members with an easy to use flow chart when making release decisions which frames empirically-derived decision factors in the basis of evidence. Board members can then review offenders' case files/conduct a parole interview examining decision factors from the position that these factors are either aggravating, or mitigating (or neutral) to their risk of recidivism. Because this Framework is grounded in empirical evidence, the decisions that paroling authorities are immediately more defensible from outside criticism, it enhances board member agreement and increases the transparency of the organization.

Using structured decision guidelines can also lead to more accurate decisionmaking. Research validating the Structured Release Decision Framework has found a 4$6 \%$ improvement in decision factors in a variety of offender types (Serin \& Gobeil, in preparation). Furthermore, when retroactively implementing the Framework on board of investigation cases, the Framework yielded a 40\% improvement in accuracy (Serin, 
2007). Clearly this is an area of interest for paroling authorities, as increases in accuracy can lead to reduced victimization rates and less money being spent of the associated costs of crime.

Supervision Decisions. Over and above release decisions, paroling authorities often make decisions regarding the supervision requirements of parolees. This usually involves decisions regarding the amount and type of parole conditions which are placed on the offender in order to manage their risk in the community.

Over the past sixty years there has been some research examining the use of parole conditions for community supervision. In the first survey of its kind, Arluke (1956) surveyed 45 American states and found that some paroling authorities place as many as 20-30 parole conditions on offenders. Over the years, these surveys were replicated with the number of conditions fluctuating (Arluke, 1969; Travis \& Latessa, 1982), with the most recent survey finding that paroling authorities, on average, place 18.6 conditions on offenders. This is in contrast with the current findings, where the average number of mandatory parole conditions (e.g., parole conditions which apply to all offenders) being 7.36 and with the inclusion of special parole conditions (e.g., parole conditions directed towards the unique needs and characteristics of the individual offender) the average number being 12.9.

While there appears to be a decrease in the number of parole conditions being utilized by paroling authorities, the number of parole conditions is still quite large. There is a common misconception that the more conditions placed on the offender, the safer the community will be; however, this is not the case. When the number of parole conditions 
are too numerous they can serve as roadblocks to offender rehabilitation (Petersilisa, 2001; Travis \& Stacey, 2010).

Alternatively, the purpose of parole conditions should be aid the reintegration success of the offender by targeting their individual criminogenic needs and by taking into account their assessed risk of recidivism. For example, more stringent parole conditions (e.g., placement in a residential substance abuse program) may help address particular criminogenic needs and reduce the likelihood of recidivism for higher risk offenders, these stringent conditions may actually increase the risk of recidivism for low risk offenders (Bonta, Wallace-Capretta, \& Rooney, 2000; Lowenkamp \& Latessa, 2005).

In the current research, all paroling authorities said they parole conditions as a method to manage an offender's level of risk in the community; however, it is unclear how they are doing this as just under $70 \%$ of paroling authorities link parole conditions to an offender's criminogenic needs and less than half of paroling authorities tie parole conditions to the offender's risk of recidivism (e.g., with higher risk offenders getting more conditions and lower risk offenders getting fewer parole conditions). Furthermore, only $38.5 \%$ of paroling authorities frontload parole conditions at the beginning of the supervision period when offenders are at highest risk of reoffending. And only a third of those surveyed reduce the number of parole conditions over time if the offender has been successful thus far.

It appears as if paroling authorities are under the impression that they use parole conditions as a method to manage an offender's level of risk in the community, but, in 
practice, this does not appear to be actually happening. Paroling authorities should put more effort into addressing these concerns.

Evaluation. Evaluation of parole organizations has been said to be an essential component for successful re-entry, as it is important for paroling authorities to assess whether the model they are using is effective (Campbell, 2008). The current findings suggest that many paroling authorities are developing necessary strategies to evaluate their organization's performance. Almost all paroling authorities have decision and recidivism databases, with varied information included in them. This would suggest that paroling authorities may have the ability to evaluate the effectiveness of their decision making practices.

Paroling authorities may not be fully utilizing this information; however, as the more recent work in parole has largely been policy-based work as opposed to empirical research. Future examinations of parole should place a greater importance on empirical research that utilizes paroling authority performance outcome indicators. This would provide the field greater understanding in what works for parole and contribute to a broader discussion regarding the role of parole and its potential public policy utility.

Future Development of the PQAI. The continued development of the PQAI will have to balance the need for reliability and validity. The current project saw the items included in the PQAI be reduced for the sake of reliability. All paroling authorities, for example, indicated that they assessed offender risk. As there was no variability in responses for this item, it was removed from the reduced version of the PQAI as it did not contribute to the reliability of the measure. An expanse of past research, however, has illustrated the importance of utilizing risk assessment instruments (Meehl, 1996; Hanson, 
2009). Therefore, it can be argued that this item should remain in the PQAI. When developing the next version of the PQAI, further discussions with the advisory panel should occur to distinguish relevant items that should remain in the PQAI, even if they do not contribute to the reliability of the measure.

\section{Limitations and Future Directions}

As the current project was exploratory in nature, there were a number of limitations that should be acknowledged. The findings were limited by the small sample size. The population of paroling authorities is already limited, and given the other lengthy survey which was released in close proximity to the current study; it is possible that paroling authorities were not willing to participate in further research. Irrespective of why participation was lower than hoped, the small sample size leads to a number of limitations. In particular, the results of the current study are unable to be generalized to other paroling authorities as it is possible that the paroling authorities that participated differ in some way from those who did not. Furthermore, the small sample size led to under-powered analyses, resulting in difficulty interpreting results with confidence. Future validation of this quality measure should ensure greater participation from paroling authorities, so that the psychometric properties, factor structure, and correlations with performance outcome indicators can be analysed with greater confidence.

Alongside the sample size limitation, it is important to acknowledge the inherent problems associated with relying on Null Hypothesis Significance Testing using p-values when dealing with a small sample size. A common misconception is that p-values indicate the strength of the association between two variables (Gliner, Leech, \& Morgan, 2002). This is incorrect because while smaller p-values are correlated with larger effect 
sizes given unchanging sample sizes, the p-value only signifies the probability that there is an association supposing a true null hypothesis. In an attempt to circumvent this problem, it has become expected that researchers include both effect sizes and confidence intervals when reporting their findings. However, when interpreting confidence intervals, it is important for the researcher to consider the impact sample size has on these boundaries. Confidence intervals allow researchers to estimate the range of values in which the true population score sits with a predefined degree of confidence (most commonly $95 \%$ or $99 \%$ confidence; Field, 2009). When dealing with small sample sizes, it is difficult to be precise when estimating confidence intervals, as smaller sample sizes produce wider intervals. Given the small number of paroling authorities who participated in the current project, the confidence intervals associated with these findings are likely to be imprecise. If a greater number of paroling authorities are able to be recruited in future research, the confidence intervals may be able to provide a more precise estimate of the true population score.

The reliance on self-report measures may also play a role in the lack of relationship found between parole quality and outcome. A major limitation of self-report measures is that responses may include biases associated with purposeful or unconscious misrepresentation (Mills \& Hogan, 1978; Sax, 1997). It is possible that paroling authorities portrayed themselves in a more favourable light, or were simply overlyoptimistic regarding their organization's practices.

An additional step which should be taken to validate the use of the PQAI is to examine if a different type of scoring method would yield similar results. Therefore, it is proposed that, in the future, independent auditors conduct assessments of paroling 
authorities and these be compared to the paroling authorities' self-assessed PQAI scores. This is an important step to take as Conley-Tyler (2005) has examined the advantages and disadvantages of using internal evaluators (a paroling authority staff member) or external evaluators (an independent auditor). She found that internal evaluators are valued for typically being less expensive, already having an in-depth knowledge of the operations and policies of the organization, and being able to effectively communicate relevant and timely information to the organization about practical changes that can be made to improve the organization. Where internal evaluators can falter is that their closeness to the organization may make it difficult to gather information (e.g., it is easier to open up to a stranger versus your employer), they may hold unconscious values which may affect objectivity, they will be perceived as less objective in comparison to external evaluators, and they may struggle with criticizing the organization as they may fear negative consequences. In comparison, external evaluators can be selected for their expertise in a particular area, they may find it easier to gather information, and they are more likely to be perceived as objective. However, they may be more expensive than internal evaluators and they may struggle to understand the complexities of the organization, leading to an inaccurate evaluation. When evaluating a paroling authority it is important that these considerations are taken into account. Given these concerns, it is of value to examine if and how evaluations of paroling authority fidelity differ as a function of who is evaluating them.

Furthermore, it is questionable as to whether the psychometric properties of the PQAI were measured using the most appropriate method. Due to the unforeseen floor and ceiling effects in item responses (e.g., many items of the PQAI were removed from the 
revised version of the scale because of the lack of variability in responses) the revised scale is seriously diminished of, arguably, important items. The psychometric properties were measured using strategies which underlie Classical Test Theory; which suggest that a test score is made of two key elements, a true score and an error score. The error score consisting of the difference between the construct of interest (e.g., the true quality of the organization) and the observable score (e.g., the quality of the organization as measured by the PQAI; Hambleton \& Slater, 1997). There are a number of limitations to this approach; however, with the need for variance on common statistics (item difficulty, item discrimination, test reliability and test validity). If there is a lack of response variance with invalid or undefined items, some researchers have argued that classical test theory is not an appropriate approach for scale validation (Zickar \& Broadfoot, 2009). Future research regarding the validation of the PQAI should explore other options, such as itemresponse theory, in an attempt to address these concerns.

Given the difficulties with obtaining recidivism outcome data, it may be beneficial to explore alternate avenues of validation. It may be possible to integrate other expert views with other outcomes of interest. This could include examining the procedural integrity of organizations (e.g., the number of appeals and whether these appeals result in differences in board member release decisions) as a function of the degree of integrity the organization possesses. Future research using the PQAI may also want to develop scoring benchmarks in order to increase the utility of the quality measure (e.g., PQAI scores below 50\% are of unacceptable quality). More tangible feedback to paroling authorities may encourage the organization to make improvements where necessary. These are areas that call for further discussion. 


\section{Conclusion}

In summary, while the PQAI was unable to be validated, it did provide interesting information regarding current parole practices. While paroling authorities seem to have made improvements regarding the adoption of evidence-based practices, there are still advances to be made. More specifically, paroling authorities should work to increase the transparency of their organizations, develop explicit selection criteria for new staff members, adopt specialized risk assessment instruments for specific subgroups of offenders, adopt structured decision guidelines to aid board members in how they weigh decision criteria, and, finally, use parole conditions as a way to manage an offender's risk of recidivism in the community. Furthermore, future versions of the PQAI should balance the need for reliability with the need for valid items. This research project was fraught with low-powered analyses and small sample size, therefore, more research is needed to validate the PQAI. 


\section{References}

Anderson, D. B., Schumacker, R. E., \& Anderson, S. L. (1991). Release characteristics and parole success. Journal of Offender Rehabilitation, 17(1-2), 133-145. Retrieved from http://search.proquest.com/docview/618110208?accountid=9894

Andrews, D. A., \& Bonta, J. (1998). The Psychology of Criminal Conduct, Second Edition. Cincinnati, OH: Anderson Publishing Company.

Andrews, D. A., \& Bonta, J. (2006). The Psychology of Criminal Conduct, Fourth Edition. Cincinnati, OH: Anderson Publishing Company.

Andrews, D. A., \& Bonta, J. (2007). Risk-Need-Responsivity Model for Offender Assessment and Rehabilitation (2007-06). Ottawa, Canada: Public Safety Canada.

Andrews, D. A., \& Bonta, J. (2010). The Psychology of Criminal Conduct, Fifth Edition. Cincinnatie, OH: Anderson Publishing Company.

Andrews, D. A., Bonta, J., \& Wormith, J. S. (2010). The level of service (LS) assessment of adults and older adolescents. Routledge/Taylor \& Francis Group, New York, NY. Retrieved from http://search.proquest.com/docview/621565225?accountid=9894

Andrews, D. A., \& Dowden, C. (2006). Risk principle of case classification in correctional treatment: A meta-analytic investigation. International Journal of Offender Therapy and Comparative Criminology, 50(1), 88-100. doi:http://dx.doi.org/10.1177/0306624X05282556

Andrews, D. A., Zinger, I., Hoge, R. D., Bonta, J., Gendreau, P., \& Cullen, F. T. (1990). Does correctional treatment work? A clinically relevant and psychologically 
informed meta-analysis. Criminology, 28(3), 369-404. doi: 10.1111/j.17459125.1990.tb01330.x

Aos, S., Miller, M. G., \& Drake, E. (2006). Evidence-based adult corrections programs: What works and what does not. Washington State Institute for Public Policy.

Aos, S., Phipps, P., Barnoski, R., \& Lieb, R. (2001). The comparative costs and benefits of programs to reduce crime. version 4.0 Washington State Institute for Public Policy, 110 East Fifth Avenue, Suite 214, P.O. Box 40999, Olympia, WA 985040999. Retrieved from http://search.proquest.com/docview/62360227?accountid=9894

Arluke, N. R. (1956). A summary of parole rules. Crime \& Delinquency, 2(1), 6-13.

Arluke, N. R. (1969). A summary of parole rules-Thirteen years later. Crime \& Delinquency, 15(2), 267-274.

Barkdull, W. L. (1976). Probation: Call it control-and mean it. Federal Probation, 40, 3. Bengtson, S., \& Langstrom, N. (2007). Unguided clinical and actuarial assessment of reoffending risk: A direct comparison with sex offenders in denmark. Sexual Abuse: A Journal of Research and Treatment, 19(2), 135-153. doi:http://dx.doi.org/10.0007/s11194-007-9044-5

Bill C-10: Safe Streets and Communities Act (2012). Retrieved from http://www.parl.gc.ca/HousePublications/Publication.aspx?DocId=5465759

Bonczar, T. P., Maruschak, L. M., Bureau of Justice Statistics, US Department of Justice, \& Office of Justice Programs. (2013). Probation and Parole in the United States, 2012. 
Bonta, J. (1996). Risk-needs assessment and treatment. In A. T. Harland (Ed.), Choosing correctional options that work: Defining the demand and evaluating the supply (pp. 18-32). Thousand Oaks, CA: Sage.

Bonta, J., Law, M., \& Hanson, K. (1998). The prediction of criminal and violent recidivism among mentally disordered offenders: A meta-analysis. Psychological Bulletin, 123(2), 123-142. doi:http://dx.doi.org/10.1037/0033-2909.123.2.123

Bonta, J., Wallace-Capretta, S., \& Rooney, J. (2000). A quasi-experimental evaluation of an intensive rehabilitation supervision program. Criminal Justice and Behavior, 27(3), 312-329. http://dx.doi.org/10.1177/0093854800027003003

Borum, R. (1996). Improving the clinical practice of violence risk assessment: Technology, guidelines, and training. American Psychologist, 51(9), 945. http://dx.doi.org/10.1037//0003-066X.51.9.945

Bourgon, G., \& Armstrong, B. (2005). Transferring the principles of effective treatment into a "real world" prison setting. Criminal Justice and Behavior, 32(1), 3-25. doi:http://dx.doi.org/10.1177/0093854804270618

Briggs, S. R. \& Cheek, J. M. (1986). The role of factor analysis in the development and evaluation of personality scales. Journal of Personality, 54, 106-148.

Brown, S. L., Amand, M. D. S., \& Zamble, E. (2009). The dynamic prediction of criminal recidivism: A three-wave prospective study. Law and Human Behavior, 33(1), 25-45. doi:http://dx.doi.org/10.1007/s10979-008-9139-7

Bumby, K., Carter, M., Talbot, T., \& Gilligan, L. (2007). The Comprehensive Assessment Protocol: A systemwide review of adult and juvenile sexual offender management strategies. Silver Spring, MD: Center for Sex Offender Management. 
Burke, P. B. (2011). The Future of Parole as a Key Partner in Assuring Public Safety. US Department of Justice, National Institute of Corrections.

Burke, P. B., Giguere, R., Gilligan, L., \& Center for Effective Public Policy. (2011).Special Challenges Facing Parole. US Department of Justice, National Institute of Corrections.

Burke, P. B., \& Tonry, M. H. (2006). Successful transition and reentry for safer communities: A call to action for parole. Center for Effective Public Policy.

Campbell, N. M. (2008). Comprehensive framework for paroling authorities in an era of evidence-based practice. Washington, DC: National Institute of Corrections.

Campbell, M. A., French, S., \& Gendreau, P. (2009). The prediction of violence in adult offenders. A meta-analytic comparison of instruments and methods of assessment. Criminal Justice and Behavior, 36(6), 567-590.

doi:http://dx.doi.org/10.1177/0093854809333610

Caplan, J. M. (2007). What factors affect parole: A review of empirical research. Federal Probation, 71(1), 16-19. Retrieved from

http://search.proquest.com/docview/621817485?accountid=9894

Carter, M., (2011). Evidence-Based Policy, Practice, and Decisionmaking. US Department of Justice, National Institute of Corrections.

Center for Effective Public Policy, Pretrial Justice Institute, The Justice Management Institute, and The Carey Group. 2010. Survey of Public Opinion on Evidence-Based Decision Making in Local Criminal Justice Systems. Unpublished report. Washington, DC: U.S. Department of Justice, National Institute of Corrections. 
Cochrane, A. L., (1972). Effectiveness and Efficiency: Random Reflections on Health Services, London, England: Royal Society of Medicine Press.

Colorado State Board of Parole (2013). State Board of Parole Decisions: FY 2013 Report. Retrieved from http://www.colorado.gov/ccjjdir/Resources/Resources/Report/2013-11_SB11241Rpt.pdf

Conley-Tyler, M. (2005). A fundamental choice: internal or external evaluation. Evaluation Journal of Australasia, 4(1/2), 3-11.

Corrections and Conditional Release Act (S.C. 1992, c.20, s.100)

Corrections and Conditional Release Act (S.C. 1992, c.20, s.102)

Deming, W. E., (1989). Out of the crisis. Cambridge: MA: MIT Center for Advanced Engineering.

Desmarais, S.L. \& Singh, J.P. (2013). Risk Assessment Instruments Validated and Implemented in Correctional Settings in the United States. Council of State Governments Justice Center

De Vries Robbé, M., de Vogel, V., \& de Spa, E. (2011). Protective factors for violence risk in forensic psychiatric patients: A retrospective validation study of the SAPROF. The International Journal of Forensic Mental Health, 10(3), 178-186. doi:http://dx.doi.org/10.1080/14999013.2011.600232

Douglas, K. S., \& Kropp, P. R. (2002). A prevention-based paradigm for violence risk assessment: Clinical and research applications. Criminal Justice and Behavior, 29(5), 617-658. doi:http://dx.doi.org/10.1177/009385402236735 
Farnworth, M., \& Horan, P. M. (1980). Separate justice: An analysis of race differences in court processes. Social Science Research, 9(4), 381-399. http://dx.doi.org/10.1016/S0049-089X(80)80004-4

Field, A. (2009). Discovering statistics using SPSS. Sage publications.

Friendship, C., Mann, R. E., \& Beech, A. R. (2003). Evaluation of a national prisonbased treatment program for sexual offenders in England and Wales. Journal of Interpersonal Violence, 18(7), 744-759.

http://dx.doi.org/10.1177/0886260503018007004

Fukurai, H. (1996). Race, social class, and jury participation: New dimensions for evaluating discrimination in jury service and jury selection. Journal of Criminal Justice, 24(1), 71-88. doi:http://dx.doi.org/10.1016/0047-2352(95)00053-4

Garcia-Mansilla, A., Rosenfeld, B., \& Cruise, K. R. (2011). Violence risk assessment and women: Predictive accuracy of the HCR-20 in a civil psychiatric sample. Behavioral Sciences \& the Law, 29(5), 623-633. doi:http://dx.doi.org/10.1002/bsl.1005

Gendreau, P. \& Andrews, D.A. (1994). The correctional program assessment inventory. Gendreau, P., \& Goggin, C. (1996). Principles of effective correctional programming. In Forum on Corrections Research (Vol. 8, pp. 38-41). Correctional Service of Canada.

Gendreau, P., Goggin, C., \& Annis, H. (1990). Survey of existing substance abuse programs. In Forum on Corrections Research (Vol. 2, p. 608).

Glaze, L. E., \& Kaeble, D. (2014). Correctional populations in the United States, 2013. U.S. Department of Justice. 
Gliner, J. A., Leech, N. L., \& Morgan, G. A. (2002). Problems with null hypothesis significance testing (NHST): What do the textbooks say? Journal of Experimental Education, 71(1), 83-92. Retrieved from http://search.proquest.com/docview/619938301? accountid=9894

Gobeil, R. (2006). Factors influencing parole decision making: Demographic characteristics, cognitive style, and offender type. (Order No. MR18264, Carleton University (Canada)). ProQuest Dissertations and Theses, 112-112 p. Retrieved from http://search.proquest.com/docview/305351636?accountid=9894. (305351636).

Gobeil, R. (2012). Understanding parole recommendations: The contribution of parole officers. (Order No. NR93702, Carleton University (Canada)). ProQuest Dissertations and Theses, 296. Retrieved from http://search.proquest.com/docview/1367212685?accountid=9894. (1367212685).

Gobeil, R., \& Serin, R. C. (2009). Preliminary evidence of adaptive decision making techniques used by parole board members. The International Journal of Forensic Mental Health, 8(2), 97-104. doi:http://dx.doi.org/10.1080/14999010903199258

Gordon, A., \& Nicholaichuk, T. (1996). Applying the risk principle to sex offender treatment. In Forum on Corrections Research, 8(2), pp. 36-38.

Gottfredson, D. M. (1978). Classification for parole decision policy. ().Superintendent of Documents, U.S. Government Printing Office, Washington, D.C., 20402 (Stock no. 027-000-00688-4). Retrieved from http://search.proquest.com/docview/63756051 accountid=9894 
Gottfredson, D. M., \& Ballard, K. B. (1966). Differences in parole decisions associated with decision-makers. Journal of Research in Crime and Delinquency, 3(2), 112119. http://dx.doi.org/10.1177/002242786600300204

Hambleton, R. K., \& Slater, S. C. (1997). Item response theory models and testing practices: Current international status and future directions. European Journal of Psychological Assessment, 13(1), 21-28. doi:http://dx.doi.org/10.1027/10155759.13 .1 .21

Hanson, R. K. (2009). The psychological assessment of risk for crime and violence. Canadian Psychology, 50(3), 172-182. Retrieved from http://search.proquest.com/docview/220815086? accountid=9894

Hanson, R. K., \& Morton-Bourgon, K. (2009). The accuracy of recidivism risk assessments for sexual offenders: A meta-analysis of 118 prediction studies. Psychological Assessment, 21(1), 1-21. doi:http://dx.doi.org/10.1037/a0014421

Hardyman, P. L., \& Van Voorhis, P. (2004). Developing gender-specific classification systems for women offenders. US Dept. of Justice, National Institute of Corrections.

Hawkins, K. (1973). Parole procedure: An alternative approach. British Journal of Criminology, 13(1), 6-25. Retrieved from http://search.proquest.com/docview/60068007?accountid=9894

Heilbrun, K., Goldstein, N. E. S., \& Redding, R. E. (2005). Juvenile delinquency: Prevention, assessment, and intervention. Oxford University Press, USA.

Henrichson, C., \& Delaney, R. (2012). The price of prisons: What incarceration costs taxpayers. Federal Sentencing Reporter, 25(1), 68-80. 
Herberman, E. J., Bonczar, T. P., Bureau of Justice Statistics, US Department of Justice, \& Office of Justice Programs. (2015). Probation and Parole in the United States, 2013.

Hilton, N. Z., Harris, G. T., Popham, S., \& Lang, C. (2010). Risk assessment among incarcerated male domestic violence offenders.Criminal Justice and Behavior, 37(8), 815-832. doi:http://dx.doi.org/10.1177/0093854810368937

Hilton, N. Z., Harris, G. T., Rice, M. E., Lang, C., Cormier, C. A., \& Lines, K. J. (2004). A brief actuarial assessment for the prediction of wife assault recidivism: The Ontario Domestic Assault Risk Assessment. Psychological Assessment, 16, $267-$ 275 .

Hinz, T., \& Pezdek, K. (2001). The effect of exposure to multiple lineups on face identification accuracy. Law and Human Behavior, 25(2), 185-198. doi:http://dx.doi.org/10.1023/A:1005697431830

Ho, H., Thomson, L., \& Darjee, R. (2009). Violence risk assessment: The use of the PCL-SV, HCR-20, and VRAG to predict violence in mentally disordered offenders discharged from a medium secure unit in scotland. Journal of Forensic Psychiatry \& Psychology, 20(4), 523-541. doi:http://dx.doi.org/10.1080/14789940802638358

Hoffman, P. B. (1972). Paroling policy feedback. Journal of Research in Crime and Delinquency, 9(2), 117-133. http://dx.doi.org/10.1177/002242787200900205

Hoge, R. D., Andrews, D. A., \& Leschied, A. W. (1996). An investigation of risk and protective factors in a sample of youthful offenders. Child Psychology \& Psychiatry \& Allied Disciplines, 37(4), 419-424. http://dx.doi.org/10.1111/j.14697610.1996.tb01422.x 
Holland, T. R., \& Holt, N. (1978). Utilization of offender case information by "lenient" vs "punitive" clinicians. Journal of Clinical Psychology, 34(3), 798-808. http://dx.doi.org/10.1002/1097-4679(197807)34:3\%3C798::AIDJCLP2270340348\%3E3.0.CO;2-W

Holsinger, A. M. (1999). Opening the 'black box': Assessing the relationship between program integrity and recidivism (Doctoral dissertation, University of Cincinnati).

Huebner, B. M., \& Bynum, T. S. (2008). The role of race and ethnicity in parole decisions. Criminology, 46(4), 907. Retrieved from http://search.proquest.com/docview/220700222? accountid=9894

Hughes, T. A., \& Wilson, D. J. (2003). Reentry trends in the United States. US Department of Justice, Bureau of Justice Statistics.

Johnson, J. E., Friedmann, P. D., Green, T. C., Harrington, M., \& Taxman, F. S. (2011). Gender and treatment response in substance use treatment-mandated parolees. Journal of Substance Abuse Treatment, 40(3), 313-321. doi:http://dx.doi.org/10.1016/j.jsat.2010.11.013

Kaltsounakis, Z. (1995). Implementing total quality management in Canadian health care: an empirical investigation (Doctoral dissertation), Concordia University: Montreal.

Kinnevy, S. C., \& Caplan, J. M. (2008a). Findings from the APAI international survey of releasing authorities. Philadelphia: Center for Research on Youth and Policy.

Kinnevy, S. C., \& Caplan, J. M. (2008b). National Surveys of State Parole Boards: Models of Service Delivery. 
Kroner, D. G., Mills, J. F., \& Reddon, J. R. (2005). A coffee can, factor analysis, and prediction of antisocial behavior: The structure of criminal risk. International Journal of Law and Psychiatry, 28(4), 360-374. Retrieved from http://search.proquest.com/docview/38186884?accountid=9894

Kröner, C., Stadtland, C., Eidt, M., \& Nedopil, N. (2007). The validity of the violence risk appraisal guide (VRAG) in predicting criminal recidivism. Criminal Behaviour and Mental Health, 17(2), 89-100. doi:http://dx.doi.org/10.1002/cbm.644

Kroner, D. G., \& Yessine, A. K. (2013). Changing risk factors that impact recidivism: In search of mechanisms of change. Law and Human Behavior, 37(5), 321-336. doi:http://dx.doi.org/10.1037/lhb0000022

Landenberger, N. A., \& Lipsey, M. W. (2005). The positive effects of cognitivebehavioral programs for offenders: A meta-analysis of factors associated with effective treatment. Journal of experimental criminology, 1(4), 451-476.

Latimer, J., \& Desjardins, N. (2007). The 2007 National Justice Survey: Tackling Crime and Public Confidence. Department of Justice Canada.

Liebling, A., (2004). Prisons and their moral performance: A study of values, quality, and prison life. Oxford: Oxford University Press.

Lizotte, A. J. (1978). Extra-legal factors in chicago's criminal courts: Testing the conflict model of criminal justice. Social Problems, 25(5), 564-580. http://dx.doi.org/10.1525/sp.1978.25.5.03a00110

Lloyd, C. D., Hanby, L. J., \& Serin, R. C. (2014). Rehabilitation group coparticipants' risk levels are associated with offenders' treatment performance, treatment change, 
and recidivism. Journal of Consulting and Clinical Psychology, 82(2), 298-311. doi:http://dx.doi.org/10.1037/a0035360

Lowenkamp, C. T., \& Latessa, E. J. (2004). Investigating the relationship between program integrity and correctional program effectiveness. University of Cincinnati.

Lowenkamp, C. T., \& Latessa, E. J. (2005). Increasing the effectiveness of correctional programming through the risk principle: Identifying offenders for residential placement. Criminology \& Public Policy, 4(2), 263-290.

doi:http://dx.doi.org/10.1111/j.1745-9133.2005.00021.x

Lowenkamp, C. T., Latessa, E. J., \& Smith, P. (2006). Does correctional program quality really matter? The impact of adhering to the principles of effective intervention. Criminology \& Public Policy, 5(3), 575-594. http://dx.doi.org/10.1111/j.1745-9133.2006.00388.x

Lytle, D. J. (2013). Decision making in criminal justice revisited: Toward a general theory of criminal justice. (Order No. 3597613, University of Cincinnati). ProQuest Dissertations and Theses, 228. Retrieved from http://search.proquest.com/docview/1458306169?accountid=9894. (1458306169).

Makarios, M., Sperber, K. G., \& Latessa, E. J. (2014). Treatment dosage and the risk principle: A refinement and extension. Journal of Offender Rehabilitation, 53(5), 334-350. doi:http://dx.doi.org/10.1080/10509674.2014.922157

Matthews, B., Hubbard, D. J., \& Latessa, E. (2001). Making the next step: Using evaluability assessment to improve correctional programming. The Prison Journal, 81(4), 454-472. http://dx.doi.org/10.1177/0032885501081004003 
Marques, J. K., Wiederanders, M., Day, D. M., Nelson, C., \& van Ommeren, A. (2005). Effects of a relapse prevention program on sexual recidivism: Final results from california's sex offender treatment and evaluation project (SOTEP).Sexual Abuse: Journal of Research and Treatment, 17(1), 79-107. doi:http://dx.doi.org/10.1177/107906320501700108

McIntosh, A. (2003, May 30). Parole officials reject judges' criticisms. National Post Retrieved from http://search.proquest.com/docview/330187896?accountid=9894

Meehl, P. E. (1996). Clinical versus statistical prediction: A theoretical analysis and a review of the evidence. Northvale, NJ: Jason Aronson. (Original work published 1954)

Mills, C. \& Hogan, R. (1978). A role theoretical interpretation of personality scale item responses. Journal of Personality, 46, 778-785.

Mullane, J. V. (2002). The mission statement is a strategic tool: When used properly. Management Decision, 40(5), 448-455. doi:http://dx.doi.org/10.1108/00251740210430461

National Institute of Corrections. (2014). Training for correctional professionals. Retrieved from www.nicic.gov/training/\#Community National Parole Resource Center. (2013). Paroling authority self-assessment toolkit. Retrieved from http://nationalparoleresourcecenter.org/toolkit2/

Nesovic, A. (2003). Psychometric evaluation of the correctional program assessment inventory (CPAI). (Order No. AAINQ83525,Dissertation Abstracts International: Section B: The Sciences and Engineering, , 4674. Retrieved from 
http://search.proquest.com/docview/620618500?accountid=9894. (620618500;

2004-99006-038).

Nunnally, J. C. (1978). Psychometric theory ( $3^{\text {rd }}$ ed.). New York: McGraw-Hill.

O'Leary, V., \& Nuffield, J. (1973). A national survey of parole decision-making. Crime and Delinquency, 19(3), 378-393.

doi:http://dx.doi.org/10.1177/001112877301900308

Orbis Partners, Inc. (2006). Women Offender Case Management Model. US Department of Justice, National Institute of Corrections.

Paparozzi, M. A., \& Caplan, J. M. (2009). A profile of paroling authorities in america:

The strange bedfellows of politics and professionalism. The Prison Journal, 89(4), 401-425. doi:http://dx.doi.org/10.1177/0032885509349559

Paparozzi, M., \& Demichele, M. (2008). Probation and parole: Overworked, misunderstood, and under-appreciated: But why? Howard Journal of Criminal Justice, 47(3), 275-296. doi:http://dx.doi.org/10.1111/j.1468-2311.2008.00522.x

Parole Board of Canada. (2009). Parole applications for provincial/territorial offenders.

Retrieved from http://pbc-clcc.gc.ca/infocntr/pa/parole_app-eng.shtml

Parole Board of Canada. (2010a). Employment at the pbc. Retrieved from http://www.pbc-clcc.gc.ca/employ/selcrit-brd-eng.shtml

Parole Board of Canada. (2010b). Fact sheet. Retrieved from http://www.pbcclcc.gc.ca/infocntr/factsh/rls-eng.shtml

Parole Board of Canada. (2013a). Board member competencies profile. Unpublished report. 
Parole Board of Canada. (2013b). Performance monitoring report 2012-2013. Retrieved from http://www.pbc-clcc.gc.ca/rprts/pmr/pmr_2012_2013/index-eng.shtml

Parole Board of Canada. (2014a). Parole Board of Canada Policy Manual (Volume 1 No. 28). Retrieved from http://www.pbc-clcc.gc.ca/infocntr/policym/polmaneng.shtml

Parole Board of Canada (2014b). 2013-2014 Departmental Performance Report. Retrieved from http://pbc-clcc.gc.ca/rprts/dpr/2013-2014/dpr-web-eng.pdf Petersilia, J. (2001). When prisoners return to communities. Federal Probation, 65(1), 38. Retrieved from http://search.proquest.com/docview/619627710?accountid=9894 PEW Charitable Trusts. (2013). The impact of parole in new jersey. Retrieved from http://www.pewtrusts.org/en/research-and-analysis\#list/12d5aa3f-2697-4e8a-9b3bb3b45ab36b57/all/0

Pfeifer, J. E., \& Ogloff, J. R. P. (1991). Ambiguity and guilt determinations: A modern racism perspective. Journal of Applied Social Psychology, 21(21), 1713-1725. Retrieved from http://search.proquest.com/docview/37976460?accountid=9894

Pogrebin, M. R., Poole, E. D., \& Regoli, R. M. (1986). Parole decision making in colorado. Journal of Criminal Justice, 14(2), 147-155.

http://dx.doi.org/10.1016/0047-2352(86)90062-0

Porporino, F. J., Robinson, D., Millson, B., \& Weekes, J. R. (2002). An outcome evaluation of prison-based treatment programming for substance users. Substance use \& Misuse, 37(8-10), 1047-1077. doi:http://dx.doi.org/10.1081/JA-120004165

Public Safety Canada Portfolio Corrections Statistics Committee. (2014). Corrections and conditional release overview. 
Rabih, J. (1998). TQM implementation in health care: a proposed framework (Doctoral dissertation), Concordia University: Monreal.

Rennie, C. E., \& Dolan, M. C. (2010). The significance of protective factors in the assessment of risk. Criminal Behaviour and Mental Health, 20(1), 8-22. doi:http://dx.doi.org/10.1002/cbm.750

Rice, M. E., Harris, G. T., \& Lang, C. (2013). Validation of and revision to the VRAG and SORAG: The violence risk appraisal Guide - Revised (VRAGR). Psychological Assessment, 25(3), 951-965. doi:http://dx.doi.org/10.1037/a0032878

Roberts, J. V., Nuffield, J., \& Hann, R. (2000). Parole and the public: Attitudinal and behavioural responses. University of Ottawa, Department of Criminology.

Rogers, R. (2000). The uncritical acceptance of risk assessment in forensic practice. Law and Human Behavior, 24(5), 595-605.

doi:http://dx.doi.org/10.1023/A:1005575113507

Rogers, J. W., \& Hayner, N. S. (1968). Optimism and accuracy in the perception of selected parole prediction items. Social Forces, 46(3), 388-400. http://dx.doi.org/10.2307/2574887

Sacks, H. R. (1976). Promises, Performance, and Principles: An Empirical Study of Parole Decisionmaking in Connecticut. Connecticut Law Review, 9, 347.

Samra, J. (1997). Parole decision-making: Cognitive biases and consistency in recommendations for conditional release suitability (Order No. MQ30552). Available from ProQuest Dissertations \& Theses Global. (304440104). Retrieved from http://search.proquest.com/docview/304440104?accountid=9894 
Samra-Grewal, J., Pfeifer, J. E., \& Ogloff, J. R. P. (2000). Recommendations for conditional release suitability: Cognitive biases and consistency in case management officers' decision-making. Canadian Journal of Criminology, 42(4), 421-447. Retrieved from http://search.proquest.com/docview/216102774?accountid=9894

Sax, G. (1997). The measurement of personality traits. In S. Horne, (Ed.), Principles of educational and psychological measurement and evaluation $\left(4^{\text {th }}\right.$ ed; pp. 520-521). Toronto, ON: Wadsworth Publishing Company.

Schwartzapfel, B. (2015, July 11). How parole boards keep prisoners in the dark and behind bars. The Washington Post. Retrieved from http://www.washingtonpost.com/national/the-power-and-politics-of-paroleboards/2015/07/10/49c1844e-1f71-11e5-84d5-eb37ee8eaa61_story.html

Scott, J. E. (1974). The use of discretion in determining the severity of punishment for incarcerated offenders. The Journal of Criminal Law and Criminology (1973), 65(2), 214-224. http://dx.doi.org/10.2307/1142540

Serin, R. C. (2004). Release Decision-Making Manual. Unpublished manuscript.

Serin R. C. (2007a). Application of parole decision-making framework to board of investigation cases. Unpublished report. Carleton University, Ottawa, Ontario.

Serin, R. C. (2007b). The Dynamic Risk Assessment Scale for Offender Re-Entry (DRAOR). Unpublished scale. Carleton University, Ottawa, Ontario.

Serin, R. C., \& Lloyd, C. (2009). Examining the process of offender change: The transition to crime desistance. Psychology, Crime and Law, 15(4), 347-364. doi:http://dx.doi.org/10.1080/10683160802261078 
Serin, R. C., \& Lowenkamp, C. T. (in press). Drug court practitioner fact sheet: Selecting and using risk and need assessments. National Drug Court Institute.

Serin, R. C., \& Mausser, C. (2012, May). How do parole conditions related to evidencebased practice. Workshop presented at the Association of Paroling Authorities International Training Conference, Orlando: FL.

Serin, R. C., Wardrop, K., \& Mausser, C. (in preparation). An international survey of paroling authorities: Factors that influence parole conditions.

Skeem, J. L., \& Monahan, J. (2011). Current directions in violence risk assessment. Current Directions in Psychological Science, 20(1), 38-42. http://dx.doi.org/10.1177/0963721410397271

Stroker, R. (2010). Core Competencies: A Resource for Parole Board Chairs, Members, and Executive Staff. P. Burke, \& L. Gilligan (Eds.). US Department of Justice, National Institute of Corrections.

Stroker, R. (2011). Paroling Authorities' Strategic Planning and Management for Results. US Department of Justice, National Institute of Corrections.

Taylor, E. L. (1979). In search of equity: The oregon parole matrix impact of the movement for greater sentence determinacy on oregon parole practice. Federal Probation, 43, 52-59. Retrieved from http://search.proquest.com/docview/59083115?accountid=9894

The Associated Press. (2007, July 25). Conn. suspects had no history of violent crimes. USA Today, Retrieved from http://usatoday30.usatoday.com/news/nation/2007-0723-conn-home-invasion_N.htm 
Travis, L. F., \& Latessa, E. J. (1984). “A summary of parole rules-Thirteen years later”: Revisited thirteen years later. Journal of Criminal Justice, 12(6), 591-600.

Travis, L. F., \& Stacey, J. (2010). A half century of parole rules: Conditions of parole in the united states, 2008. Journal of Criminal Justice, 38(4), 604-608. doi:http://dx.doi.org/10.1016/j.jcrimjus.2010.04.032

Unnever, J. D., Frazier, C. E., \& Henretta, J. C. (1980). Race differences in criminal sentencing. The Sociological Quarterly, 21(2), 197-205. http://dx.doi.org/10.1111/j.1533-8525.1980.tb00604.x

Van Voorhis, P., \& Presser, L. (2001). Classification of women offenders: A national assessment of current practices. Washington, DC: U.S. Department of Justice, National Institute of Corrections.

Valentine, J., Gottlieb, B., Keel, S., Griffith, J., \& Ruthhazer, R. (1998). Measuring the effectiveness of the urban youth connection: The case for dose-response modeling to demonstrate the impact of an adolescent substance abuse prevention program. The Journal of Primary Prevention, 18(3), 363-386. Retrieved from http://search.proquest.com/docview/619302402? accountid=9894

Venkatraman, S. (2007). A framework for implementing TQM in higher education programs. Quality Assurance in Education, 15(1), 92-112.

Vogel, V. D., Ruiter, C. D., Bouman, Y., \& Vries Robbé, M. D. (2009). SAPROF. In Guidelines for the assessment of protective factors for violence risk. English Version. Utrecht, The Netherlands: Forum Educatief. 
Webster, C., Douglas, K., Eaves, D., \& Hart, S. (1997). HCR-20: Assessing Risk for Violence (Version 2). Vancouver, British Columbia, Canada: Simon Fraser University.

Webster, C. D., Harris, G. T., Rice, M. E., Cormier, C., \& Quinsey, V. L. (1994). Violence risk appraisal guidedoi:http://dx.doi.org/10.1037/t02743-000

Webster, C. D., Martin, M., Brink, J., Nicholls, T. L., \& Desmarais, S. L., (2009). Manual for the Short Term Assessment of Risk and Treatability (START) (Version 1.1). Coquitlam, Canada: British Columbia Mental Health \& Addiction Services. West-Smith, M., Pogrebin, M. R., \& Poole, E. D. (2000). Denial of parole: An inmate perspective. Federal Probation, 64, 3.

Wilson, C. M., Desmarais, S. L., Nicholls, T. L., Hart, S. D., \& Brink, J. (2013). Predictive validity of dynamic factors: Assessing violence risk in forensic psychiatric inpatients. Law and Human Behavior, 37(6), 377-388. doi:http://dx.doi.org/10.1037/lhb0000025

Wright, K. N., Clear, T. R., \& Dickson, P. (1984). Universal applicability of probation risk-assessment instruments: A critique. Criminology, 22(1), 113-134. http://dx.doi.org/10.1111/j.1745-9125.1984.tb00291.x

Yang, M., Wong, S. C., \& Coid, J. (2010). The efficacy of violence prediction: A metaanalytic comparison of nine risk assessment tools. Psychological Bulletin, 136(5), 740-767. Retrieved from http://search.proquest.com/docview/757171372? accountid=9894 
Zickar, M. J., \& Broadfoot, A. A. (2009). The partial revival of a dead horse? Comparing classical test theory and item response theory. Statistical and methodological myths and urban legends, 37-61. 


\section{Appendix A - Parole Quality Assurance Inventory}

Paroling authorities are an integral part of criminal justice systems worldwide. Every year, for thousands of offenders, these authorities make numerous decisions regarding the timing of release and conditions that are placed on offenders. Additionally, they respond to parole violations for many more.

Given the large numbers of offenders that are involved in the criminal justice system, of whom approximately $95 \%$ will eventually be released into the community, it is critical that paroling authorities employ decision-making strategies that will give offenders the probability of reducing recidivism (Hughes \& Wilson, 2003). Past research has shown that when evidence-based correctional practices are used, it is possible to reduce recidivism by up to $30 \%$ (Andrews \& Bonta, 2006). These evidence-based practices are critical to ensuring efficient and effective Paroling Authorities.

The purpose of this survey is to examine aspects of paroling authorities and how they function in order to better define high quality paroling systems. Efforts will be made to validate this survey by examining its relationship to various parole performance indicators. The results of the survey will be confidentially shared with participating agencies, as well as comparative information regarding other paroling authorities. Part A: Mission/Vision

1. Does the paroling authority have a vision statement (i.e., a broad statement that identifies the organization's proposed direction)?

No

Somewhat

__ Yes, clear written statement

N 
2. Within the mission statement(s) (i.e., a statement(s) that clearly indicates how the organization will operate in light of their vision) how does the paroling authority prioritize public safety?

There is no mission statement

There is a mission statement; however, it does not take into account community

safety

There is a mission statement; however, it only takes into account community

safety in terms of decisions, but recognizes offender rehabilitation can also lead to

higher success rates in parole

$\mathrm{N} / \mathrm{A}$

3. Does the mission statement require linking various corrections and parole partners (e.g., Department of Corrections, community supervision partners)?

No

- Yes

$\mathrm{N} / \mathrm{A}$

4. Does the paroling authority do community outreach?

No

Y Yes

N/A

5. Does the paroling authority do media relations?

No

Yes

N/A 
6. Does the paroling authority sit on criminal justice boards?

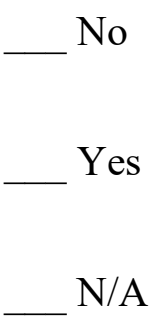

7. Does the paroling authority have regular (e.g., monthly) meetings with any of the following organizations:

a. Police?

No

Y Yes

b. Corrections?

No

_ Yes

c. Community supervision partners?

No

Y Yes
d. $\quad$ N/A

8. Does the parole authority have a strategic plan (i.e., a systematic process of implementing the mission statement)?

No

Somewhat

Yes, clear written.

N $\mathrm{N} / \mathrm{A}$ 
9. Is there a plan or method to operationalize the goals of the strategic plan?

No

Somewhat

_ Yes, clear written

N/A

10. If yes, how often is the strategic plan or method reviewed?

It is not reviewed

__ Monthly

_ Quarterly

_ Annually

N N/A

11. If yes, is the strategic plan available online?

No

_ Yes (intranet)

Yes (internet)

N/A

Part B: Organizational Structure

1. Number of years under the present chair

2. Number of years of experience the present chair has

3. What past experience does the present chair have? (check all that apply)

__ Parole Board

Corrections

Court System (law enforcement, lawyer, etc.) 
Other (please specify

N/A

4. Are there criteria for new parole chair selection? (check all that apply) Decision-making (not restricted to parole) Addictions

Mental Health

_Legal/Policy/Statutes

L_ Leadership

Human Resources

Criminal Justice Knowledge

Political Affiliation

Other (please specify

N/A

5. How many parole board members are there?

6. What proportion of board members are:

Part-time

Full-time

$\mathrm{N} / \mathrm{A}$

7. What is the average number of years spent on the Board?

8. Are there criteria for new board member selection?

No

Somewhat

Y Yes, written criteria 
Yes, explicit written criteria

N/A

a. If so, check all that apply.

A degree in the human sciences (law, criminology, psychology, etc.)

Knowledge of the criminal justice system and the associated issues

Comprehensive decision-making skills

Extensive communication skills

Strong ethical fortitude

Political affiliation

Other (please specify

$\mathrm{N} / \mathrm{A}$

b. On a scale of 1-6 (with 1 being most important and 6 being least important), rate the importance placed on board member criteria.

A degree in the human sciences (law, criminology, psychology, etc.)

Knowledge of the criminal justice system and the associated issues

Comprehensive decision-making skills

__ Extensive communication skills

_

_ Political affiliation

Other (please specify

N/A

9. Is board member competency considered prior to their appointment, through interview or other standardized assessment method? 
_ No

_ Somewhat

_ Yes

N/A

10. Following initial training, is board member competency measured, through interview or other standardized assessment method prior to their making decisions?

No

_ Somewhat

- Yes

N/A

11. Do the demographics of the board members match the demographics of the jurisdiction?

No

_ Somewhat

_ Yes

I don’t know

N/A

12. What is the duration of a parole board appointment?

13. Is there a process for board members' terms to be renewed?

- No

- Yes

N/A

14. If yes, what is the typical renewal term? _ years _ N/A 
15. If yes, which factors are considered? Check all that apply

Political Affiliation

Demonstrated Competence

Criminal Justice Knowledge

Unique Perspective (e.g., victim rights advocate, etc.)

Other

N/A

16. How are Board members compensated?

Board members are not compensated

Per diem

_ Hourly wage

Annual Salary

N/A

17. Does the paroling authority independently manage its budget?

No

Y Yes

N/A

18. Do any of the following factors influence budget allocation?

Sensational cases

Number of decisions

Size of prison population 
_ Decision-making capacity (\# of board members vs. \# of decisions)

Other (please specify

N N/A

19. Does the Paroling Authority complete an annual report?

No

_ Yes (standalone report)

_ Yes (incorporated in government report)

N N/A

20. Does the Paroling Authority release an annual report?

_ No

__ Yes (government website)

_ Yes (written report to the Governor or others)

N/A

21. Is there legislation that provides a legal mandate for the existence of the parole board?

- No

- Yes

N/A

Part C: Staff Training

1. Is training/mentoring protocols provided for the Chair during their tenure? (check all that apply)

Decision-making (parole specific) 
_Legal/Policy/Statutes

Leadership

_ Human Resources

_ Risk Assessment

Other (please specify

N/A

2. Is training/mentoring protocols provided for Board Members during their tenure? (check all that apply)

_ Decision-making (parole specific)

Legal/Policy/Statutes

Leadership

Human Resources

_ Risk Assessment

Other (please specify $\mathrm{N} / \mathrm{A}$

3. Do new board members receive initial training? If so, typically how many hours in the first three months on the job? N/A

4. If yes, what kind of initial training is offered? Check all that apply.

Reading training materials

_ Mentoring provided by a senior parole board member

One week of NIC training plus mentoring provided by a senior parole board

member

_ Pre-service training with the Department of Corrections

Other (please specify 
N/A

5. What training topics are covered in initial training? (check all that apply and the duration of training)

Risk assessment

_ 0 days __ 1 day _ _ 1-2 days _ greater than 2 days

Decision-making

_ 0 days __ 1 day _ $1-2$ days __ greater than 2 days

Victims of crime

_ 0 days __ 1 day __ $1-2$ days __ greater than 2 days

Offender needs

0 days __ 1 day __ 1-2 days __ greater than 2 days

Offender Programming

0 days __ 1 day __ $1-2$ days __ greater than 2 days

Community Supervision

_ 0 days __ 1 day _ $1-2$ days __ greater than 2 days Sex Offenders

_ 0 days __ 1 day __ 1-2 days __ greater than 2 days

Domestic Violence

_ 0 days __ 1 day __ $1-2$ days __ greater than 2 days

Other Specialized needs issues

_ 0 days __ 1 day __ $1-2$ days __ greater than 2 days

Other (please specify:

$\mathrm{N} / \mathrm{A}$ 
6. Who provides the initial training to board members?

Parole Board

Department of Corrections

Other (please specify: e.g. external consultants

N/A

7. Do board members get ongoing/yearly training days?

No

- Yes

N/A

a. If yes, how many days/hours per year are set aside for training? _ _ N/A

b. If yes, what form does this training come in? (check all that apply)

Workshops

Conferences

_ Self-development courses (online)

_ Mentoring

On-the-job Training

Other (please specify:

_ N/A

c. If yes, who provides the ongoing training to board members?

__ Parole Board

Department of Corrections

Other (please specify: e.g. external consultants N/A 
d. If yes, what training topics are covered? (check all that apply and the duration of training)

Risk assessment

$$
\text { _ } 0 \text { days __ } 1 \text { day _ } 1-2 \text { days __ greater than } 2 \text { days }
$$

Decision-making

_ 0 days __ 1 day __ 1-2 days __ greater than 2 days

Victims of crime

_ 0 days __ 1 day __ 1-2 days __ greater than 2 days

Offender needs

_ 0 days __ 1 day __ 1-2 days __ greater than 2 days

Offender Programming

_ 0 days __ 1 day __ 1-2 days __ greater than 2 days

Community Supervision

_ 0 days __ 1 day __ 1-2 days __ greater than 2 days

Sex Offenders

$$
\text { _ } 0 \text { days __ } 1 \text { day __ 1-2 days __ greater than } 2 \text { days }
$$

Domestic Violence

_ 0 days __ 1 day __ 1-2 days __ greater than 2 days

Specialized needs issues

0 days __ 1 day __ 1-2 days __ greater than 2 days

Other (please specify:

N/A

8. Upon initially being hired, are new board members mentored by those more senior to them? 
$\begin{array}{llll}1 & 3 & 4\end{array}$

Not at all

Extensively

9. Is mentoring provided on an ongoing basis for board members?

1

$2 \quad 3 \quad 4$

Not at all

Extensively

Part D: Decision Making Process

1. Who has the decision authority for parole decisions?

Parole Chair

Parole Board member

Governor or senior state official

Other government official

N/A

2. Can the decision authority veto Board Member decisions?

No

_ Yes, specific to offense types (e.g., homicide, sex offenses, etc.)

Yes, for all decisions

N/A

3. Does the paroling authority have a mechanism in place to track the amount of time decision-makers spend preparing for each case?

No

Yes

$\mathrm{N} / \mathrm{A}$ 
4. What is the average preparation time decision-makers are allotted to examine a case?

Less than 15 minutes

15-30 minutes

_ 30-60 minutes

More than 60 minutes

$\mathrm{N} / \mathrm{A}$

5. What is the average number of cases that the parole board member is expected to review/make decisions on per day? N/A

6. How many cases are parole board members expected to review/make decisions on per week? N/A

7. How are offenders included in the decision process?

Case files only (no offender contact)

Telephone/video appearance

In-person appearance (no restrictions)

In-person appearance (select criteria, e.g., offense criteria)

$\mathrm{N} / \mathrm{A}$

8. Is the offender represented during the decision process?

No

Y Yes

$\mathrm{N} / \mathrm{A}$

9. If yes, who provides offender representation during the decision process? No one

Separate offender input 
Department of Corrections

Family/attorney speaking on offender's behalf

L_ Letters/other correspondence

Other (please specify

$\mathrm{N} / \mathrm{A}$

10. Can offenders have legal assistance during the parole decision process?

No

Yes

$\mathrm{N} / \mathrm{A}$

11. Can offenders have legal representation during the parole decision process (assesses rules of evidence, cross-examination of facts)?

No

Y Yes

N/A

12. Do policy and/or statutes define what specific release criteria paroling authorities should be taking into account?

No

- Yes

N N/A

a. If yes, are these provided to the offender?

No

Y Yes

N/A 
b. If yes, check all that apply

Age of first offense

__ Seriousness of current offense

__ Persistence and versatility of criminal behaviour

_ Criminal behaviour increasing in severity

__ Institutional adjustment

_ Marital/family relationships as they relate to risk to reoffending

_ School/work and leisure activities as they relate to risk to reoffending

_ System/background factors which may have contributed to criminal

behaviour (e.g., substance abuse, systemic discrimination, unemployment, dysfunctional family life, etc.)

History of reoffending on conditional release

_ History of breaching conditions on conditional release

_ History of escape/escape attempts

Victim information

Actuarial measures of the risk to reoffend

_ Information regarding behavior in correctional institution/program completion

Release plan and community management strategies Other (please specify N/A

13. Are there structured decision guidelines regarding these factors to assist board members in parole decisions? No 
Yes

N/A

14. When making a parole decision, what importance does your agency place on the type of crime?

1 2 3 4

Not important Very important

15. Is there importance placed on the type of crime reflected in policy and/or statutes?

No

_ Yes

N/A

16. Do policy and/or statutes provide decision guidelines for paroling authorities?

No

Yes

N/A

17. If yes, which policy and/or statutes inform paroling authorities? (check all that apply)

Eligibility (timing)

Number of release conditions (e.g., $\min / \max$ )

Type of release conditions (mandatory)

_ Type of release conditions (special)

Decision Factors (the specific factors they should be taking into account)

_ Decision Factors (the weight they should place on these factors)

N/A 
18. Does the paroling authority/corrections department have a website that informs the general public/offender about parole?

No

Yes

N/A

19. Are victims of the offender permitted to be involved in the decision process?

No

Y Yes

N/A

20. If yes, how are victims of the offender permitted to be involved in the decision process?

Written statement only

Oral statement only

Either/both written or oral statement

N/A

21. Are board members given specific guidelines on what weight they should place on victim impact statements when making their decision?

No

Yes

N/A

22. Is reduction of parole conditions used as an incentive for good behaviour for parolees by Board members?

No

Yes 
$\mathrm{N} / \mathrm{A}$

23. Is shortened length of parole supervision used as an incentive for good behaviour for parolees by Board members?

No

Yes

N/A

24. Does the parole board have any policy/statute-determined frequency of contact standards for supervision (e.g., lower risk = less frequent contact)?

No

Y Yes

$\mathrm{N} / \mathrm{A}$

25. Which agency has authority for frequency of contact standards?

Department of Corrections

Parole Board

Both

N/A

26. How many conditions are mandatorily imposed on offenders in your jurisdiction? N/A

27. What is the approximate average number of conditions per case (mandatory + special conditions)? N/A

28. Are parole conditions used to hold offenders accountable?

- No

Y Yes

N/A 
29. If yes, how? (check all that apply)

Ensure offender compliance

__ Ensure offender motivation

__ Reduce over time with supervision success

30. Are parole conditions used to manage offender risk?

No

Y Yes

N N/A

31. If yes, how? (check all that apply)

Lower risk offenders receive fewer parole conditions

Higher risk offenders receive more parole conditions

Parole conditions are linked to criminogenic needs

_ Parole conditions are linked to the offenders' release plan

Frontloading of conditions (i.e., more conditions at initial release)

32. Are decision-makers required to provide a written rationale for their decision?

No

__ Yes (summary)

Yes (detailed decision)

N/A

33. Are there appeal or redress procedures in place for offenders to utilize?

No

_ Yes (select cases)

_ Yes (all cases) 
N/A

Part E: Risk Assessment

1. Are there risk measures available for the parole board to assess offender risk? Offender risk is not measured or unstructured clinical judgement is used to measure risk

Structured professional judgement is used to measure risk

__ Yes, a statistical risk scale using only static factors

__ Yes, a statistical risk scale using only static and dynamic factors

_ Y Yes, a statistical risk scale using static, dynamic, and protective factors

N/A

2. If yes, list the measure(s) used

3. When making a parole decision, what importance do you place on the risk assessment score or rating?

$1 \quad 2 \quad 3 \quad 4$

Not important $\quad$ Very important

4. To your knowledge has the risk assessment instrument(s) been validated on your offender population?

No

Y Yes

Unsure

N/A

5. Are there specialized risk instruments for particular types of offenders? (check all that apply)

Ethnic subgroups/Indigenous Offenders 
Sex Offenders

__ Mentally Disordered Offenders

__ Domestic Violence Offenders

__ Women Offenders

__ Substance Abuse Offenders

N/A

6. Do the risk measures you use classify offenders as being low, moderate, or high risk for recidivism?

No

_ Yes

N/A

7. Do the risk measures provide a probability estimate (\%) of likelihood of failure?

No

_ Yes

N/A

8. Does the level of assessed risk influence your decision-making in any way?

$\begin{array}{llll}1 & 2 & 3 & 4\end{array}$

Not at all

Significantly

Part F: Violation Process

1. Who has authority to consider parole violations?

_ Parole Chair

__ Parole Board Member

Parole Supervisor 
Parole Officer

$\mathrm{N} / \mathrm{A}$

2. How are offenders included in the parole violation decision process? Case files only (no offender contact)

Telephone/video appearance

In-person appearance (select criteria)

_ In-person appearance (all criteria)

N/A

3. Is the offender represented during the parole violation decision process?

No

Y Yes

N/A

4. Who provides offender representation during the parole violation decision process?

Separate offender input

Department of Corrections

___ Family/attorney speaking on offender's behalf

Letters/other correspondence

Other (please specify

N/A

5. Can offenders have legal assistance during the parole violation decision process? No

Yes 
N/A

6. Can offenders have legal representation during the parole violation decision process (assesses rules of evidence, cross-examination of facts)?

No

Y Yes

N/A

7. Do policy and/or statutes define what specific criteria paroling authorities should be taking into account when dealing with parole violations?

No

Yes (specific to violations)

Yes (specific to type of crime/offender)

N/A

a. If yes, are these provided to the offender?

No

Y Yes

N $\mathrm{N} / \mathrm{A}$

b. If yes, do they include:

Actuarial measures of the risk to reoffend

Seriousness of current violation

Past criminal behavior trends

The offender's correctional or offender accountability plan progress while in the community and identified needs and risk factors

Any documented episodes of drug use or positive urinalysis tests 
The circumstances surrounding the parole violation

The release plan and community management strategies for continuing the release

Parole officer recommendation

Other (please specify

N/A

8. Are there structured decision guidelines regarding these factors to assist board members in parole violation decisions?

No

Yes

$\mathrm{N} / \mathrm{A}$

9. Do policy and/or statutes provide structured decision guidelines for paroling authorities in parole violation decisions?

No

Y Yes

N/A

10. Are decision-makers required to provide a written rationale for their violation decision?

_ No

Y Yes

N N/A

11. How are parole violations processed?

Paper Decision

_ No paper decisions 
Some paper decisions

All paper decisions

_ Parole Hearing

No hearing decisions

Some hearing decisions

_ All hearing decisions

N/A

12. Are there appeal or redress procedures in place for parole violators to utilize?

No

Y Yes

N N/A

Part G: Evaluation

1. Does the paroling authority have/maintain a parole decisions database?

No

Y Yes

N/A

2. Who maintains this database?

_ Paroling Authority

Corrections

Other (please specify:

N/A

3. What does this database include? 
_ Decisions only

Decisions and conditions imposed on offender

_ Decisions, conditions imposed on offender, and reasons given for decision

N/A

4. Do you keep data regarding recidivism outcomes?

No

Y Yes

N/A

5. Do you have access to data regarding aggregated recidivism outcomes?

No

_ Yes

N/A

6. Do you have access to data regarding recidivism outcomes for individual cases?

No

_ Yes

N/A

7. Who maintains the recidivism database?

Paroling Authority

Corrections

Other (please specify: 
8. What is included in the recidivism database? (check all that apply)

Violations of parole conditions

Revocation due to parole violations

New crimes

New violent crimes

Absconders

_ Technical violations

N/A

9. Do you convert recidivism data to cost benefits?

No

Yes

$\mathrm{N} / \mathrm{A}$

10. Does the paroling authority include performance indicators in its annual report?

No

Yes

$\mathrm{N} / \mathrm{A}$

11. Can the public access information about decisions?

The public cannot access this information

By written request only

Website

Other (please specify:

$\mathrm{N} / \mathrm{A}$ 
12. Does the paroling authority maintain an online website that reports performance indicators?

No

Y Yes

N/A

Section H: Confidence in accuracy of the information

1. Rate the degree of confidence you have in the above evaluation.

$\begin{array}{llllllllll}1 & 2 & 3 & 4 & 5 & 6 & 7 & 8 & 9 & 10\end{array}$

Not at all Extremely

Confident

2. Are there other areas/questions that you would like to see audited under this type of Parole Quality Assurance Project? (list all) 
Appendix B - Parole Quality Assurance Inventory: Reduced Items

$*=$ retained item

Paroling authorities are an integral part of criminal justice systems worldwide.

Every year, for thousands of offenders, these authorities make numerous decisions regarding the timing of release and conditions that are placed on offenders. Additionally, they respond to parole violations for many more.

Given the large numbers of offenders that are involved in the criminal justice system, of whom approximately $95 \%$ will eventually be released into the community, it is critical that paroling authorities employ decision-making strategies that will give offenders the probability of reducing recidivism (Hughes \& Wilson, 2003). Past research has shown that when evidence-based correctional practices are used, it is possible to reduce recidivism by up to $30 \%$ (Andrews \& Bonta, 2006). These evidence-based practices are critical to ensuring efficient and effective Paroling Authorities.

The purpose of this survey is to examine aspects of paroling authorities and how they function in order to better define high quality paroling systems. Efforts will be made to validate this survey by examining its relationship to various parole performance indicators. The results of the survey will be confidentially shared with participating agencies, as well as comparative information regarding other paroling authorities. Part A: Mission/Vision

1. *Does the paroling authority have a vision statement (i.e., a broad statement that identifies the organization's proposed direction)?

No

Somewhat 
_ Yes, clear written statement

N/A

2. Within the mission statement(s) (i.e., a statement(s) that clearly indicates how the organization will operate in light of their vision) how does the paroling authority prioritize public safety?

There is no mission statement

There is a mission statement; however, it does not take into account

community safety

There is a mission statement; however, it only takes into account community

safety in terms of decisions, but recognizes offender rehabilitation can also lead to higher success rates in parole

N N/A

3. Does the mission statement require linking various corrections and parole partners (e.g., Department of Corrections, community supervision partners)?

No

_ Yes

N/A

4. *Does the paroling authority do community outreach?

_ No

_ Yes

N/A

5. *Does the paroling authority do media relations?

No

Yes

N/A 
6. Does the paroling authority sit on criminal justice boards?

No
Yes
N/A

7. Does the paroling authority have regular (e.g., monthly) meetings with any of the following organizations:

a. Police?

No

Y Yes

b. Corrections?

No

_ Yes

c. Community supervision partners?

No

Y Yes

d. $\quad$ N/A

8. *Does the parole authority have a strategic plan (i.e., a systematic process of implementing the mission statement)?

_ No

_ Somewhat

_ Yes, clear written.

N/A

9. *Is there a plan or method to operationalize the goals of the strategic plan? No 
_ Somewhat

_ Yes, clear written

N/A

10. *If yes, how often is the strategic plan or method reviewed?

It is not reviewed

Monthly

__ Quarterly

Annually

N/A

11. *If yes, is the strategic plan available online?

No

Y Yes (intranet)

_ Yes (internet)

N/A

Part B: Organizational Structure

1. Number of years under the present chair

2. Number of years of experience the present chair has

3. What past experience does the present chair have? (check all that apply)

Parole Board

Corrections

_ Court System (law enforcement, lawyer, etc.)

__ Other (please specify ___ _

N/A 
4. *Are there criteria for new parole chair selection? (check all that apply)

* ___ Decision-making (not restricted to parole)

_ Addictions

_ Mental Health

* ___ Legal/Policy/Statutes

* ___ Leadership

_ Human Resources

* ___ Criminal Justice Knowledge

*___ Political Affiliation

_ Other (please specify

* N/A

5. How many parole board members are there?

6. What proportion of board members are:

Part-time

__ Full-time

N N/A

7. What is the average number of years spent on the Board?

8. Are there criteria for new board member selection?

No

_ Somewhat

_ Yes, written criteria

_ Yes, explicit written criteria

N/A 
a. *If so, check all that apply.

A degree in the human sciences (law, criminology, psychology, etc.)

* K__ Knowledge of the criminal justice system and the associated issues Comprehensive decision-making skills

Extensive communication skills

_ Strong ethical fortitude

Political affiliation

Other (please specify

* $\mathrm{N} / \mathrm{A}$

b. On a scale of 1-6 (with 1 being most important and 6 being least important), rate the importance placed on board member criteria.

A degree in the human sciences (law, criminology, psychology, etc.)

Knowledge of the criminal justice system and the associated issues

Comprehensive decision-making skills

Extensive communication skills

_ Strong ethical fortitude

_ Political affiliation

Other (please specify

N/A

9. *Is board member competency considered prior to their appointment, through interview or other standardized assessment method?

_ No

__ Somewhat

_ Yes 
N/A

10. *Following initial training, is board member competency measured, through interview or other standardized assessment method prior to their making decisions?

No

Somewhat

_ Yes

N/A

11. Do the demographics of the board members match the demographics of the jurisdiction?

No

Somewhat

Y Yes

I don't know

N/A

12. What is the duration of a parole board appointment?

13. Is there a process for board members' terms to be renewed?

No

Y Yes

N/A

14. If yes, what is the typical renewal term? __ years __ N/A

15. *If yes, which factors are considered? Check all that apply

*__ Political Affiliation

* ___ Demonstrated Competence

* ___ Criminal Justice Knowledge 
*___ Unique Perspective (e.g., victim rights advocate, etc.)

Other

* N N/A

16. How are Board members compensated?

Board members are not compensated

Per diem

_ Hourly wage

__ Annual Salary

N $\mathrm{N} / \mathrm{A}$

17. Does the paroling authority independently manage its budget?

No

Y Yes

N

18. *Do any of the following factors influence budget allocation?

_ Sensational cases

* ___ Number of decisions

* ___ Size of prison population

* ___ Decision-making capacity (\# of board members vs. \# of decisions)

* ___ Other (please specify

* N N/A

19. Does the Paroling Authority complete an annual report?

No

_ Y Yes (standalone report)

_ Yes (incorporated in government report) 
N/A

20. Does the Paroling Authority release an annual report?

_ No

_ Yes (government website)

_ Yes (written report to the Governor or others)

N/A

21. Is there legislation that provides a legal mandate for the existence of the parole board?

No

_ Yes

N/A

Part C: Staff Training

1. *Is training/mentoring protocols provided for the Chair during their tenure? (check all that apply)

* ___ Decision-making (parole specific)

* ___ Legal/Policy/Statutes

* ___ Leadership

*__ Human Resources

*__ Risk Assessment

_ Other (please specify

* $\mathrm{N} / \mathrm{A}$

2. *Is training/mentoring protocols provided for Board Members during their tenure? (check all that apply)

* ___ Decision-making (parole specific) 
*__ Legal/Policy/Statutes

* ___ Leadership

* ___ Human Resources

*___ Risk Assessment

__ Other (please specify

* $\quad$ N/A

3. Do new board members receive initial training? If so, typically how many hours in the first three months on the job? $\mathrm{N} / \mathrm{A}$

4. *If yes, what kind of initial training is offered? Check all that apply.

* ___ Reading training materials

Mentoring provided by a senior parole board member

One week of NIC training plus mentoring provided by a senior parole board

member

_ Pre-service training with the Department of Corrections

* __ Other (please specify

* N N/A

5. *If yes, what training topics are covered? (check all that apply)

_ Risk assessment

Decision-making

Victims of crime

Offender needs

Offender Programming

Community Supervision

_ 
* Domestic Violence

*___ Specialized needs issues

Other (please specify:

* N N/A

a. What is the duration of the risk assessment training?

_ 0 days __ 1 day __ 1-2 days __ greater than 2 days

b. What is the duration of the decision-making training?

_ 0 days __ 1 day __ 1-2 days __ greater than 2 days

c. What is the duration of the victims of crime training?

_ 0 days __ 1 day __ 1-2 days __ greater than 2 days

d. What is the duration of the offender needs training?

0 days __ 1 day __ $1-2$ days __ greater than 2 days

e. What is the duration of offender programming training?

_ 0 days __ 1 day __ 1-2 days __ greater than 2 days

f. What is the duration of the community supervision training?

0 days __ 1 day __ 1-2 days __ greater than 2 days

g. What is the duration of the sex offenders training?

_ 0 days __ 1 day __ 1-2 days __ greater than 2 days

h. What is the duration of the domestic violence training?

0 days __ 1 day __ 1-2 days __ greater than 2 days

i. What is the duration of the specialized needs issues training?

_ 0 days __ 1 day __ 1-2 days __ greater than 2 days

j. What is the duration of the "other" training? 
_ 0 days _ 1 day _ _ $1-2$ days __ greater than 2 days

6. Who provides the initial training to board members?

_ Parole Board

__ Department of Corrections

Other (please specify: e.g. external consultants

N/A

7. *Do board members get ongoing/yearly training days?

No

Y Yes

N/A

8. If yes, how many days/hours per year are set aside for training?

$\mathrm{N} / \mathrm{A}$

9. If yes, what form does this training come in? (check all that apply)

__ Workshops

Conferences

_ Self-development courses (online)

_ Mentoring

On-the-job Training

Other (please specify:

N/A

10. If yes, who provides the ongoing training to board members?

_ Parole Board

Department of Corrections

Other (please specify: e.g. external consultants

N/A 
11. *If yes, what training topics are covered? (check all that apply)

* ___ Risk assessment

* ___ Decision-making

* ___ Victims of crime

* ___ Offender needs

* ___ Offender Programming

*___ Community Supervision

* __ Sex Offenders

*___ Domestic Violence

* ___ Specialized needs issues

Other (please specify:

* N N/A

di. What is the duration of the risk assessment training?

_ 0 days __ 1 day __ $1-2$ days __ greater than 2 days

dii. What is the duration of the decision-making training?

_ 0 days __ 1 day __ 1-2 days __ greater than 2 days

diii. What is the duration of the victims of crime training?

_ 0 days __ 1 day __ 1-2 days __ greater than 2 days

div. What is the duration of the offender needs training?

_ 0 days __ 1 day __ 1-2 days __ greater than 2 days

$\mathrm{dv}$. What is the duration of offender programming training?

_ 0 days __ 1 day __ $1-2$ days __ greater than 2 days

dvi. What is the duration of the community supervision training?

_ 0 days __ 1 day __ 1-2 days __ greater than 2 days 
dvii. What is the duration of the sex offenders training?

_ 0 days __ 1 day __ $1-2$ days __ greater than 2 days

dviii. What is the duration of the domestic violence training?

_ 0 days __ 1 day __ $1-2$ days __ greater than 2 days

dix. What is the duration of the specialized needs issues training?

_ 0 days __ 1 day __ $1-2$ days __ greater than 2 days

$\mathrm{dx}$. What is the duration of the "other" training?

_ 0 days __ 1 day __ $1-2$ days __ greater than 2 days

12. Upon initially being hired, are new board members mentored by those more senior to them?

$\begin{array}{llll}1 & 2 & 3\end{array}$

Not at all Extensively

13. Is mentoring provided on an ongoing basis for board members?

$1 \quad 2 \quad 3 \quad 4$

Not at all Extensively

Part D: Decision Making Process

1. Who has the decision authority for parole decisions?

__ Parole Chair

_ Parole Board member

Governor or senior state official

Other government official

N 
2. *Can the decision authority veto Board Member decisions?

No

_ Y Yes, specific to offense types (e.g., homicide, sex offenses, etc.)

_ Y Yes, for all decisions

N/A

3. Does the paroling authority have a mechanism in place to track the amount of time decision-makers spend preparing for each case?

- No

Y Yes

N/A

4. What is the average preparation time decision-makers are allotted to examine a case?

_ Less than 15 minutes

_ 15-30 minutes

_ 30-60 minutes

More than 60 minutes

N/A

5. What is the average number of cases that the parole board member is expected to review/make decisions on per day? $\mathrm{N} / \mathrm{A}$

6. How many cases are parole board members expected to review/make decisions on per week? N/A

7. How are offenders included in the decision process?

Case files only (no offender contact)

Telephone/video appearance

In-person appearance (no restrictions)

__ In-person appearance (select criteria, e.g., offense criteria) 
N/A

8. Is the offender represented during the decision process?

No
Yes
N/A

9. If yes, who provides offender representation during the decision process?

No one

__ Separate offender input

_ Department of Corrections

Family/attorney speaking on offender's behalf

Letters/other correspondence

Other (please specify

N/A

10. Can offenders have legal assistance during the parole decision process?

No
Yes
N/A

11. *Can offenders have legal representation during the parole decision process (assesses rules of evidence, cross-examination of facts)?

No
Yes
N/A

12. Do policy and/or statutes define what specific release criteria paroling authorities should be taking into account? 
No

_ Yes

N/A

c. If yes, are these provided to the offender?

No

Y Yes

N/A

d. *If yes, check all that apply

Age of first offense

Seriousness of current offense

* ___ Persistence and versatility of criminal behaviour

* __ Criminal behaviour increasing in severity

Institutional adjustment

_ Marital/family relationships as they relate to risk to reoffending

School/work and leisure activities as they relate to risk to reoffending

*___ System/background factors which may have contributed to criminal

behaviour (e.g., substance abuse, systemic discrimination, unemployment, dysfunctional family life, etc.)

*___ History of reoffending on conditional release

* ___ History of breaching conditions on conditional release

History of escape/escape attempts

Victim information

Actuarial measures of the risk to reoffend 
__ Information regarding behavior in correctional institution/program completion

__ Release plan and community management strategies Other (please specify

N/A

13. *Are there structured decision guidelines regarding these factors to assist board members in parole decisions?

- No

- Yes

N/A

14. *When making a parole decision, what importance does your agency place on the type of crime?

$\begin{array}{llll}1 & 2 & 3 & 4\end{array}$

Not important $\quad$ Very important

15. *Is there importance placed on the type of crime reflected in policy and/or statutes?

- No

_ Yes

N/A

16. Do policy and/or statutes provide decision guidelines for paroling authorities?

- No

- Yes

N N/A

17. *If yes, which policy and/or statutes inform paroling authorities? (check all that apply) 
* ___ Eligibility (timing)

_ Number of release conditions (e.g., $\min / \max$ )

_ Type of release conditions (mandatory)

* ___ Type of release conditions (special)

Decision Factors (the specific factors they should be taking into account)

* ___ Decision Factors (the weight they should place on these factors)

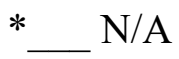

18. Does the paroling authority/corrections department have a website that informs the general public/offender about parole?

No

Y Yes

N/A

19. Are victims of the offender permitted to be involved in the decision process?

No

Y Yes

N/A

20. If yes, how are victims of the offender permitted to be involved in the decision process?

Written statement only

_ Oral statement only

Either/both written or oral statement

N/A

21. *Are board members given specific guidelines on what weight they should place on victim impact statements when making their decision?

No 
Y Yes

N/A

22. Is reduction of parole conditions used as an incentive for good behaviour for parolees by Board members?

No

Y Yes

N $\mathrm{N} / \mathrm{A}$

23. Is shortened length of parole supervision used as an incentive for good behaviour for parolees by Board members?

No

Y Yes

N/A

24. Does the parole board have any policy/statute-determined frequency of contact standards for supervision (e.g., lower risk = less frequent contact)?

No

Y Yes

N/A

25. Which agency has authority for frequency of contact standards?

Department of Corrections

Parole Board

Both

N/A

26. How many conditions are mandatorily imposed on offenders in your jurisdiction? N/A

27. What is the approximate average number of conditions per case (mandatory + special conditions)? N/A 
28. Are parole conditions used to hold offenders accountable?

No

Y Yes

N/A

29. If yes, how? (check all that apply)

__ Ensure offender compliance

Ensure offender motivation

_ Reduce over time with supervision success

30. Are parole conditions used to manage offender risk?

No

Y Yes

N/A

31. *If yes, how? (check all that apply)

*___ Lower risk offenders receive fewer parole conditions

* ___ Higher risk offenders receive more parole conditions

_ Parole conditions are linked to criminogenic needs

* ___ Parole conditions are linked to the offenders' release plan

*___ Frontloading of conditions (i.e., more conditions at initial release)

32. Are decision-makers required to provide a written rationale for their decision?

No

_ Yes (summary)

_ Yes (detailed decision)

N/A

33. *Are there appeal or redress procedures in place for offenders to utilize? 
No

_ Yes (select cases)

_ Yes (all cases)

$\mathrm{N} / \mathrm{A}$

Part E: Risk Assessment

1. Are there risk measures available for the parole board to assess offender risk? Offender risk is not measured or unstructured clinical judgement is used to measure risk Structured professional judgement is used to measure risk Yes, a statistical risk scale using only static factors Yes, a statistical risk scale using only static and dynamic factors Yes, a statistical risk scale using static, dynamic, and protective factors $\mathrm{N} / \mathrm{A}$

2. If yes, list the measure(s) used

3. When making a parole decision, what importance do you place on the risk assessment score or rating?

$\begin{array}{llll}1 & 2 & 3 & 4\end{array}$

Not important

Very important

4. To your knowledge has the risk assessment instrument(s) been validated on your offender population?

No

Y Yes

Unsure

N/A 
5. *Are there specialized risk instruments for particular types of offenders? (check all that apply)

__ Ethnic subgroups/Indigenous Offenders

_ Sex Offenders

* ___ Mentally Disordered Offenders

Domestic Violence Offenders

__ Women Offenders

* ___ Substance Abuse Offenders

N/A

6. Do the risk measures you use classify offenders as being low, moderate, or high risk for recidivism?

No

Y Yes

N/A

7. *Do the risk measures provide a probability estimate $(\%)$ of likelihood of failure?

_ No

_ Yes

N/A

8. Does the level of assessed risk influence your decision-making in any way?

1

Not at all
23

3

4

Significantly

Part F: Violation Process

1. Who has authority to consider parole violations?

Parole Chair 


_ Parole Board Member
$\ldots$ Parole Supervisor
_ Parole Officer
N/A

2. How are offenders included in the parole violation decision process?

__ Case files only (no offender contact)

_ Telephone/video appearance

_ _ In-person appearance (select criteria)

_ In-person appearance (all criteria)

N/A

3. Is the offender represented during the parole violation decision process?

- No

_ Yes

N/A

4. Who provides offender representation during the parole violation decision process?

_ Separate offender input

_ Department of Corrections

__ Family/attorney speaking on offender's behalf

__ Letters/other correspondence

__ Other (please specify ___

N/A

5. Can offenders have legal assistance during the parole violation decision process? No 
Y Yes

N/A

6. Can offenders have legal representation during the parole violation decision process (assesses rules of evidence, cross-examination of facts)?

_ No

Y Yes

N/A

7. *Do policy and/or statutes define what specific criteria paroling authorities should be taking into account when dealing with parole violations?

No

_ Yes (specific to violations)

__ Yes (specific to type of crime/offender)

N/A

c. *If yes, are these provided to the offender?

No

- Yes

N/A

d. *If yes, do they include:

* ___ Actuarial measures of the risk to reoffend

* ___ Seriousness of current violation

* ___ Past criminal behavior trends

* ___ The offender's correctional or offender accountability plan progress while in the community and identified needs and risk factors

* ___ Any documented episodes of drug use or positive urinalysis tests

* ___ The circumstances surrounding the parole violation 
* __ The release plan and community management strategies for continuing the release

* ___ Parole officer recommendation

Other (please specify

$*$ N/A

8. *Are there structured decision guidelines regarding these factors to assist board members in parole violation decisions?

No

Y Yes

N/A

9. *Do policy and/or statutes provide structured decision guidelines for paroling authorities in parole violation decisions?

No

Y Yes

N/A

10. Are decision-makers required to provide a written rationale for their violation decision?

No

Y Yes

N/A

11. How are parole violations processed? (check all that apply)

Paper Decision

_ Parole Hearing

N/A

11a. How many parole violations are processed through paper decision? 
_

Some decisions

__ All decisions

11b. How many parole violations are processed through parole hearings? No decisions Some decisions

All decisions

12. Are there appeal or redress procedures in place for parole violators to utilize?

No

_ Yes

N/A

Part G: Evaluation

1. Does the paroling authority have/maintain a parole decisions database?

_ No

Y Yes

N/A

2. *Who maintains this database?

Paroling Authority

Corrections

__ Other (please specify:

N N/A

3. What does this database include?

Decisions only 
Decisions and conditions imposed on offender

Decisions, conditions imposed on offender, and reasons given for decision

N/A

4. Do you keep data regarding recidivism outcomes?

No

Y Yes

N/A

5. *Do you have access to data regarding aggregated recidivism outcomes?

No

Y Yes

N/A

6. *Do you have access to data regarding recidivism outcomes for individual cases?

No

Y Yes

N/A

7. *Who maintains the recidivism database?

Paroling Authority

Corrections

Other (please specify:

$\mathrm{N} / \mathrm{A}$

8. *What is included in the recidivism database? (check all that apply)

Violations of parole conditions

Revocation due to parole violations

New crimes 
_ _ New violent crimes

Absconders

_ Technical violations

N/A

9. Do you convert recidivism data to cost benefits?

No

_ Yes

N/A

10. Does the paroling authority include performance indicators in its annual report?

No

Y Yes

N/A

11. Can the public access information about decisions?

The public cannot access this information

_ By written request only

Website

Other (please specify:

N/A

Section H: Confidence in accuracy of the information

1. Rate the degree of confidence you have in the above evaluation.

$\begin{array}{llllllllll}1 & 2 & 3 & 4 & 5 & 6 & 7 & 8 & 9 & 10\end{array}$

Not at all

Extremely Confident 
2. Are there other areas/questions that you would like to see audited under this type of Parole Quality Assurance Project? (list all) 